Fachbereich 5

Wirtschaftswissenschaften, Wirtschaftsinformatik und Wirtschaftsrecht

Volkswirtschaftliche Diskussionsbeiträge

Discussion Papers in Economics

No. $143-10$

October 2010

Thomas Eichner · Rüdiger Pethig

The carbon-budget approach to climate stabilization: Costeffective subglobal versus global action 


\section{Universität Siegen}

Fachbereich 5

Wirtschaftswissenschaften, Wirtschaftsinformatik und Wirtschaftsrecht

Fachgebiet Volkswirtschaftslehre

Hölderlinstraße 3

D-57068 Siegen

Germany

http://www.uni-siegen.de/fb5/vwl/

ISSN 1869-0211

Available for free from the University of Siegen website at http://www.uni-siegen.de/fb5/vwl/research/diskussionsbeitraege/

Discussion Papers in Economics of the University of Siegen are indexed in RePEc and can be downloaded free of charge from the following website:

http://ideas.repec.org/s/sie/siegen.html 


\title{
The carbon-budget approach to climate stabilization: Cost-effective subglobal versus global action*
}

\author{
Thomas Eichner \\ Department of Economics, University of Hagen \\ Rüdiger Pethig \\ Department of Economics, University of Siegen
}

\begin{abstract}
Scientific expertise suggests that mitigating extreme world-wide climate change damages requires avoiding increases in the world mean temperature exceeding $2^{\circ}$ Celsius. To achieve the two degree target, the cumulated global emissions must not exceed some limit, the so-called global carbon budget. In a two-period twocountry general equilibrium model with a finite stock of fossil fuels we compare the cooperative cost-effective policy with the unilateral cost-effective policy of restricting emissions to the global carbon budget. In its simplest form, the cost-effective global policy is shown to consist of a joint emission trading scheme in the first period (only). In sharp contrast, subglobal cost-effective regulation may require the abating country to tax its first-period consumption and to tax or subsidize its emissions in the first and/or second period.
\end{abstract}

JEL classification: H21, H23, Q54, Q58

Key words: carbon emissions, carbon budget, cooperative, unilateral, cost-effective regulation

*Eichner: Department of Economics, University of Hagen, Universitätsstr. 41, 58097 Hagen, Germany, email: thomas.eichner@fernuni-hagen.de; Pethig: Department of Economics, University of Siegen, Hölderlinstr. 3, 57068 Siegen, Germany, email: pethig@vwl.wiwi.uni-siegen.de 


\section{Introduction}

The ultimate objective of the United Nations Framework Convention on Climate Change (UNFCCC 1992) "... is to achieve ... stabilization of greenhouse gas concentrations in the atmosphere at a level that would prevent dangerous anthropogenic interference with the climate system". As carbon dioxide is the most important greenhouse gas, climate stabilization requires curbing carbon emissions through reducing the use of fossil fuels in the short and medium term.

For various reasons the economists' standard cost-benefit approach to correcting for externalities is controversial both in science and politics as a guide to climate policy (Lave 1996; Ackerman 2004). A more pragmatic and operational approach backed by some scientific evidence consists in identifying the climate stabilization target with the goal to prevent the world mean temperature from exceeding $2^{\circ}$ Celsius above pre-industrial levels. In recent years, various governments began endorsing the $2{ }^{\circ} \mathrm{C}$ limit. The Council of the European Union (2005) "... confirms that with a view to achieving the ultimate objective of the UN Framework Convention on Climate Change, the global annual mean surface temperature should not exceed $2^{\circ} \mathrm{C}$ above pre-industrial levels". Similarly, the Copenhagen Accord (UNFCCC 2009) also refers to the climate stabilization goal of the Framework Convention and recognizes "... the scientific view that the increase in global temperature should be below 2 degrees Celsius ...". According to Meinshausen et al. (2009) the $2^{\circ} \mathrm{C}$ temperature limit will be observed with reasonable probability, if the cumulated emissions until 2050 do not exceed some threshold quantity. ${ }^{1}$ Essentially that threshold is a global cap on cumulated emissions or a global 'carbon budget' (WBGU 2009; Kalkuhl and Edenhofer 2010) which suggests to identify the goal of climate stabilization with restricting global emissions to the carbon budget. With the realistic assumption that global laissez-faire emissions would exceed the carbon budget in the future, climate stabilization requires strong political action.

In the present paper we consider the carbon-budget approach as a relevant pragmatic political approach to climate stabilization. If an international climate agreement will be reached in the future at all, it will most likely be based on that approach. Climate agreements may either encompass all countries in the world (global cooperation) or only a subset of countries (subglobal action). We focus on a subglobal climate coalition that is not only capable to prevent cumulative emissions from exceeding the carbon budget, but that actually does bring down total emissions to the carbon budget. ${ }^{2}$ Clearly, we know beforehand

\footnotetext{
${ }^{1}$ Numerical estimates of that threshold are also suggested, e.g. 750 billion tons of $\mathrm{CO}_{2}$ (e.g. WBGU 2009.)

${ }^{2}$ If we take the simplified view that up to $2^{\circ}$ rise in temperature damages from climate change are very low while an increase exceeding $2^{\circ}$ would have catastrophic effects, then any regulation failing to comply
} 
that total climate stabilization costs are higher with unilateral than with cooperative action, because carbon leaks from the abating coalition to non-abating countries and because consumption and production across countries and time are more severely distorted. Yet the comparison of total costs or welfare $\operatorname{losses}^{3}$ is not at the core of our study. Rather we will analyze and compare the type and timing of regulation which restricts global emissions to the carbon budget in global and subglobal climate policies.

If the climate coalition is capable to bring down global emissions to the carbon budget (which it is in the present paper by assumption) the climate stabilization goal can be achieved in various ways, i.e. with patterns of regulation that may differ with respect to timing and/or choice of policy instruments. Hence the issue arises - with global as well as with subglobal regulation - as to which pattern of carbon budget policy is cost effective. The (sub)global carbon budget policy is cost effective, if it is the least-cost policy for the (sub)global climate coalition. The present paper aims to characterize the cost-effective policy of a subglobal climate coalition and compares that regulation with the global cost-effective solution. To this end we set up a stylized two-country two-period model with a finite stock of fossil fuels. If the countries do not cooperate, one of the countries goes it alone and the unilaterally acting country takes into account that the other country remains on its business-as-usual track.

Our focus on climate policy relates the analysis of the present paper to the issue of carbon leakage which arises, if one country's unilateral policy of curbing emissions increases the emissions in other countries. The so-called green paradox (Sinn 2008) is said to occur in the extreme case in which unilateral emission reductions increase rather than reduce aggregate world emissions, as compared to their level in the absence of that unilateral policy ${ }^{4}$. Hoel (1991), Bohm (1993), Golombek and Hoel (2004), Copeland and Taylor (2005), Di Maria and van der Werf (2005), Ishikawa and Kiyono (2006), Eichner and Pethig (2010), van der Ploeg and Withagen (2009) have analytically explored various channels and determinants of carbon leakage and the green paradox. Kalkuhl and Edenhofer (2010) employ the carbon budget approach and characterize the cost-effective (cooperative) carbon budget policy in a one-country growth model. However, to our knowledge the extant literature does not consider subglobal climate coalitions that pursue a policy of limiting cumulative global emissions.

Governments are assumed to have available emission taxes in the first and/or second with the carbon budget would be futile.

${ }^{3}$ That information is certainly desirable. However, it requires CGE analysis which is beyond the scope of the present paper.

${ }^{4} \mathrm{~A}$ more general concept of green paradox is "...that anticipation of future reductions in demand for oil and other fossil fuels will drive the ressource owners to bring forward their supply." (Gerlagh 2010). 
period or equivalently, domestic emission trading schemes. However, contrary to most related studies, governments in our model also have at their disposal emission subsidies and a sign-unconstrained tax on their country's first-period consumption. First we consider the fully cooperative 'carbon-budget approach' as a benchmark. It turns out that in this case cost effectiveness can be achieved as follows: first-period consumption and second-period emissions are left unregulated and a uniform tax is levied on first-period emissions in both countries. ${ }^{5}$ That policy is in the spirit of results from dynamic one-country models (Sinn 2008; Sinclair 1992, 1994) in which flattening the fossil fuel consumption path requires high emission taxes early on and low or no taxes later.

After having characterized the fully cooperative cost-effective benchmark solution we investigate the case of one country bringing global emissions down to the carbon budget unilaterally. We first demonstrate that if unilateral climate stabilization is feasible, the abating country has at its disposal a variety of mixed policies some of which make use of emission subsidies and/or a consumption tax. Unfortunately, the insights into patterns and timing of the cost-effective policy to be gained from the pertaining marginal optimality conditions are very limited. We therefore resort to numerical calculations which provide very rich and unexpected information on cost-effective policies. It turns out that cost-effective subglobal regulation may require the abating country (i) to tax first-period consumption - a tax that is no part of global cost-effective regulation - and (ii) to tax or subsidize emissions in the first and/or second period. Such patterns of regulation differ markedly from costeffective global regulation.

The paper is organized as follows. Section 2 outlines the model. Section 3 characterizes the cooperative cost-effective carbon-budget policy. In the first part of Section 4 we identify mixed unilateral carbon budget policies. In the second part we characterize cost-effective unilateral climate stabilization analytically and with the help of two numerical examples. Section 5 concludes.

\footnotetext{
${ }^{5}$ In our model the cost-effective allocation turns out to be unique but can be implemented by different combinations of first/second period emission taxes/subsidies as will be shown in more detail in Section 3 below. The policy variant put forward here does not require governments committing to regulation in the far future, and we therefore consider it the most natural of otherwise equivalent policies.
} 


\section{The model}

Consider a two-period model ${ }^{6}$ with two (groups of) countries $A$ and $B$. In period $t=1,2$ each country $i=A, B$ produces the output $x_{i t}^{s}$ of the consumption good $X$ with the input $e_{i t}$ of fossil fuel according to the increasing and strictly concave production function ${ }^{7}$

$$
x_{i t}^{s}=X^{i}\left(e_{i t}\right) \quad i=A, B .
$$

Country $i$ is endowed with the share $\alpha_{i} \bar{e}$ of the world stock of fossil fuel, $\bar{e}>0$, where $\left.\alpha_{A}=1-\alpha_{B} \in\right] 0,1[$. To economize on notation we envisage an aggregate price taking fossilfuel extracting firm that may be located in either country and is owned by (the residents of) both countries according to the shares $\alpha_{A}$ and $\alpha_{B}=1-\alpha_{A} \in[0,1]$ of the resource stock. Firm $F$ sells the fuel to the producers of good $X$ in both countries and transfers to their residents the shares $\alpha_{A}$ and $\alpha_{B}$, respectively, of the resource rent.

The representative consumer of country $i$ derives utility from consumption $x_{i 1}$ in period 1 and from $x_{i 2}$ in period 2 according to the intertemporal utility function

$$
u_{i}=U^{i}\left(x_{i 1}, x_{i 2}\right) \quad i=A, B
$$

which is increasing in both arguments and quasi-concave.

In each period, good $X$ and fossil fuel are traded on perfectly competitive world markets (comprising the countries $A$ and $B$ ) at prices $p_{x t}$ and $p_{e t}$, respectively. For $t=1,2$ the market clearing conditions are

$$
\begin{aligned}
x_{A t}^{s}+x_{B t}^{s} & =x_{A t}+x_{B t}, \\
e_{t} & =e_{A t}+e_{B t},
\end{aligned}
$$

where $e_{t}$ is the supply of the fossil-fuel extracting firm in period $t$. Obviously, the supplies $e_{t}$ for $t=1,2$ need to satisfy the intertemporal constraint

$$
\bar{e}=e_{1}+e_{2} .
$$

\footnotetext{
${ }^{6}$ Essentially, the model is the same as in Eichner and Pethig (2010), even though we now deal with 2 rather than 3 countries. In Eichner and Pethig (2010) the third country owns the entire stock of fossil fuel and lives on the revenues of exporting its fuel. In the present paper the residents of each of the 2 countries own a share of the world stock of fossil fuel. The two-period time horizon is chosen for reasons of analytical tractability. Eichner and Pethig (2010) show that the model is robust with respect to extending the number of periods.

${ }^{7}$ In (1) the superscript $s$ indicates quantities supplied. Upper case letters denote functions and subscripts attached to them indicate first partial derivatives. Note that the production functions (1) can be interpreted as being linear homogeneous in fossil fuel and in a domestic production factor, e.g. labor, which is in fixed supply.
} 
To regulate carbon emissions in both periods, the governments of the countries $A$ and $B$ have at their disposal two sets of instruments: (i) taxes or subsidies on the consumption of good $X$ and (ii) emission taxes, emission subsidies or cap-and-trade systems. Consider first the latter set of instruments. Given the high degree of abstraction of our model, emission taxes and cap and trade systems are equivalent, as long as the demand for permits equals supply at some non-negative permit price. Although real world cap and trade schemes obviously fail to generate negative permit prices, it is analytically convenient to allow for such negative prices which are readily interpreted as emission subsidies, of course. To avoid clutter, we will consistently take quantities (= emission caps) as primary policy parameters rather than emission prices that may take the form of emission taxes, permit prices or emission subsidies. We refer to the cap-implementing price as 'emission price', even if that price should turn out to be negative. The national cap and trade systems operate as follows. The regulator of country $i=A, B$ issues the quantity $\bar{e}_{i t}$ of emission permits in period $t=1,2$. The producers of good $X$ then need to auction one permit for each unit of emissions at price $\pi_{i t} \in \mathbb{R}$ which is endogenously determined such that the demand for permits equals the (politically fixed) supply $\bar{e}_{i t}$. Hence the governments' policy tools are the emission caps $\bar{e}_{i t}$. If country $i$ refrains from regulating emissions in period $t$, we simply set $\pi_{i t}=0$ and treat $e_{i t}$ as an endogenous variable.

The second set of policy instruments are taxes or subsidies on the consumption of good $X$. More specifically, the consumer price of good $X$ is $p_{x t}+\tau_{i t}$ for $t=1,2$ and $i=A, B$. To simplify we take $\tau_{i 1}$ to be sign-unconstrained and set $\tau_{A 2}=\tau_{B 2}=0$ w.l.o.g. Note that in one-country models taxing the demand side and the supply side of a market is equivalent. However, in our two-country model good $X$ is traded internationally (see (3)) which is why there is the option and maybe the need to manipulate demand and supply with separate fiscal instruments.

Based on the model (1)-(5) the (regulated) competitive two-country economy is described as follows. The governments carry out the mixed policies $\left(\bar{e}_{i 1}, \bar{e}_{i 2}, \tau_{i 1}\right)_{i=A, B}$ with the implied emission prices $\left(\pi_{i t}\right)_{i=A, B ; t=1,2}$. The profits of the aggregate price-taking firms are ${ }^{8}$

$$
\begin{aligned}
\Pi^{i} & :=\sum_{t}\left[p_{x t} X^{i}\left(e_{i t}\right)-\left(p_{e t}+\pi_{i t}\right) e_{i t}\right] \quad \text { for } i=A, B, \\
\Pi^{F} & :=\sum_{t} p_{e t} e_{t} .
\end{aligned}
$$

\footnotetext{
${ }^{8}$ The discount rate is set equal to zero and the fossil-fuel extracting firm incurs no extraction costs. See also Eichner and Pethig (2010).
} 
The first-order conditions of maximizing (6) and (7) read, respectively,

$$
\begin{aligned}
& \pi_{i t}=p_{x t} X_{e_{i t}}^{i}-p_{e t} \geq 0 \quad \text { for } i=A, B \quad \text { and } \quad t=1,2, \\
& p_{e 1}=p_{e 2} .
\end{aligned}
$$

The consumer maximizes utility (2) subject to her budget constraint

$$
\left(p_{x 1}+\tau_{i 1}\right) x_{i 1}+p_{x 2} x_{i 2}=y_{i}, \quad \text { where } y_{i}:=\Pi^{i *}+\alpha_{i} \Pi^{F *}+\sum_{t} \pi_{i t} \bar{e}_{i t}+\tau_{i 1} x_{i 1} .
$$

In (10), $\Pi^{i *}$ for $i=A, B$ is the maximum profit of the firm in country $i$ and $\Pi^{F *}$ is the maximum profit of the fossil-fuel extracting firm. The budget constraints can be rearranged to $\sum_{t}\left[p_{x t}\left(x_{i t}^{s}-x_{i t}\right)+p_{e}\left(\alpha_{i} \bar{e}-e_{i t}\right)\right]=0$ for $i=A, B$ which turn out to be the countries' intertemporal trade balances. Utility maximization yields

$$
\frac{U_{x_{i 2}}^{i}}{U_{x_{i 1}}^{i}}=\frac{p_{x 2}}{p_{x 1}+\tau_{i 1}} \quad \text { for } i=A, B
$$

It remains to introduce the carbon budget concept alluded to in Section 1 into our stylized model. To this end, consider total emissions in period $t=1,2$ from $(4), e_{t}=e_{A t}+e_{B t}$, and denote by $s_{t}$ the corresponding carbon dioxide concentration in the atmosphere $(=$ stock of pollution). Let $s_{0}$ be the stock of pollution at the beginning of period 1 and assume that the stock of pollution decays at the rate $\delta \in] 0,1\left[\right.$. It follows that $s_{t}=(1-\delta) s_{t-1}+e_{t}$ for $t=1,2$. Furthermore, suppose there is a threshold value, say $\bar{s}$, of the stock of pollution ${ }^{9}$ such that the world climate is 'out of control', if and only if $s_{t}>\bar{s}$ for $t=1$ or for $t=2$. Hence the carbon-budget approach amounts to regulating the emissions $e_{1}$ and $e_{2}$ such that $s_{t} \leq \bar{s}$ for $t=1,2$.

To deal with a meaningful problem, we assume

$$
\text { (i) } s_{1}^{o}=(1-\delta) s_{0}+e_{1}^{o}>0 \text { and } \quad \text { (ii) } \bar{e} \leq \bar{e}_{1}+\delta \bar{s} \text {. }
$$

Under (12i) a necessary condition for cost-effective carbon budget regulation is to set $s_{1}=\bar{s}$ or $\left.e_{1}=\bar{e}_{1}=\bar{s}-(1-\delta) s_{o} \in\right] 0, e_{1}^{o}\left[\right.$. With $s_{t}=\bar{s}$ for $t=1,2$, the equation $s_{2}=(1-$ $\delta) s_{1}+e_{2}$ yields $e_{2}=\delta \bar{s}$. In other words, taking $s_{1}=\bar{s}$ as given, $e_{2}=\delta \bar{s}$ is the maximum total second-period emission that is compatible with a stable climate. The inequalities (12) therefore imply the prospect of climate destabilization if no action is taken (12i) as well as the feasibility to stabilize the climate via carbon-budget policy (12ii). For the sake of simple wording we refer to $\bar{e}_{1}$ as the carbon budget.

\footnotetext{
${ }^{9}$ We interprete $\bar{s}$ as the upper bound of the greenhouse gas concentration in the atmosphere that would prevent dangerous anthropogenic interference with the climate system. See our discussion in the introduction.
} 


\section{Cooperative cost-effective climate stabilization}

Suppose now the countries $A$ and $B$ take joint action to prevent world emissions from exceeding total first-period emissions $\bar{e}_{1}$. To characterize analytically that particular policy of implementing $\bar{e}_{1}$ which is cost effective from the global perspective, consider a social planner who maximizes $\sum_{i=A, B} U^{i}\left(x_{i 1}, x_{i 2}\right)$ subject to (1)-(5) and subject to $e_{1} \leq \bar{e}_{1}$. The corresponding Lagrangean reads

$$
\begin{aligned}
\mathcal{L} & =\sum_{i=A, B} U^{i}\left(x_{i 1}, x_{i 2}\right)+\lambda_{x 1}\left[X^{A}\left(e_{A 1}\right)+X^{B}\left(e_{B 1}\right)-x_{A 1}-x_{B 1}\right] \\
& +\lambda_{x 2}\left[X^{A}\left(e_{A 2}\right)+X^{B}\left(e_{B 2}\right)-x_{A 2}-x_{B 2}\right]+\lambda_{e}\left(\bar{e}-e_{1}-e_{2}\right) \\
& +\lambda_{e_{1}}\left(e_{1}-e_{A 1}-e_{B 1}\right)+\lambda_{e_{2}}\left(e_{2}-e_{A 2}-e_{B 2}\right)+\bar{\lambda}\left(\bar{e}_{1}-e_{1}\right) .
\end{aligned}
$$

The first-order conditions of solving (13) yield

$$
\begin{array}{rlr}
\frac{U_{x_{i 2}}^{i}}{U_{x_{i 1}}^{i}} & =\mu_{x 2} & \text { for } i=A, B, \\
X_{e_{i 1}}^{i} & =\mu_{e}+\bar{\mu} & \text { for } i=A, B, \\
\mu_{x 2} X_{e_{i 2}}^{i} & =\mu_{e} & \text { for } i=A, B,
\end{array}
$$

where $\mu_{x 2}:=\lambda_{x 2} / \lambda_{x 1}, \mu_{e}:=\lambda_{e} / \lambda_{x 1}$ and $\bar{\mu}:=\bar{\lambda} / \lambda_{x 1}$ are positive shadow prices in terms of first-period output $X$. We make use of this information about the efficient allocation in the standard procedure of decentralization by prices and obtain

Proposition 1. Suppose the governments of the countries $i=A, B$ have at their disposal the mixed policies $\left(\bar{e}_{i 1}, \bar{e}_{i 2}, \tau_{i 1}\right)$ and they cooperate to implement the carbon budget $\bar{e}_{1}$ in a cost-effective way.

(a) The resultant competitive equilibrium exhibits the prices ${ }^{10} p_{x 1} \equiv 1$ and $p_{x 2}=: p_{x}=\mu_{x 2}$ and the following emission regulation:

(i) $\tau_{A 1}=\tau_{B 1}=0$;

(i) The emission caps $\left(\bar{e}_{i 1}, \bar{e}_{i 2}\right)$ for $i=A, B$ are chosen such that $p_{x}=\mu_{x 2}>0, \pi_{A 1}=$ $\pi_{B 1} \in \mathbb{R}, \pi_{A 2}=\pi_{B 2} \in \mathbb{R}, p_{e 1}=p_{e 2}=p_{e}=\mu_{e}-\pi_{A 2} \geq 0$ and $\pi_{A 1}-\pi_{A 2}=\bar{\mu}>0$.

(b) The equilibrium is characterized by

$$
\frac{X_{e_{A 1}}^{A}}{X_{e_{B 1}}^{B}}=\frac{X_{e_{A 2}}^{A}}{X_{e_{B}}^{B}}=1, \quad \frac{X_{e_{A 1}}^{A}}{X_{e_{A 2}}^{A}}=\frac{X_{e_{B 1}}^{B}}{X_{e_{B 2}}^{B}}=\left(1+\frac{\bar{\mu}}{\mu_{e}}\right) p_{x}, \quad \text { and } \quad \frac{U_{x_{A 2}}^{A}}{U_{x_{A 1}}^{A}}=\frac{U_{x_{B 2}}^{B}}{U_{x_{B 1}}^{B}}=p_{x}
$$

\footnotetext{
${ }^{10}$ Here we use the degree of freedom in (shadow) prices to take first period consumption of good $X$ as numeraire. We will stick to that convention $\left(p_{x 1}=1\right.$ and $\left.p_{x 2}=p_{x}\right)$ throughout the remainder of the paper.
} 
implying that

$$
\frac{U_{x_{i 2}}^{i}}{U_{x_{i 1}}^{i}}-\frac{X_{e_{i 1}}^{i}}{X_{e_{i 2}}^{i}}=-\frac{\bar{\mu} U_{x_{i 2}}^{i}}{\mu_{e} U_{x_{i 1}}^{i}} \quad \text { for } i=A, B
$$

Proposition 1 calls for some comments. First, it is interesting to note that there is no need for taxing final demand. It is cost-effective to induce the necessary shift in demand for good $X$ by supply-side regulation only. Next observe that although the assignment of Lagrange multipliers to the prices of fuel and emissions in Proposition 1(a)(ii) is not unique, all sets of equilibrium prices in Proposition 1 support one and the same equilibrium allocation. The common features of the multiple equilibrium prices are that

- in each period the emission prices are the same across countries and that

- the emission prices in period 1 are higher than in period 2 by some positive constant.

There are three types of cost-effective policies in Proposition 1.

Policy I: $\pi_{A 1}=\pi_{B 1}=\bar{\mu}>0, \pi_{A 2}=\pi_{B 2}=0$ and $p_{e}=\mu_{e}>0$. The countries $A$ and $B$ leave second-period emissions unregulated but implement emission caps $\bar{e}_{A 1}$ and $\bar{e}_{B 1}$ that are tighter than the laissez-faire emissions $e_{A 1}^{o}$ and $e_{B 1}^{o}$. These caps are met via tax or via a cap and trade scheme.

Policy II: $\pi_{A 1}=\pi_{B 1}=0, \pi_{A 2}=\pi_{B 2}=-\bar{\mu}<0$ and $p_{e}=\mu_{e}-\pi_{A 2}>0$. The countries $A$ and $B$ leave first-period emissions unregulated but implement second-period caps $\bar{e}_{A 2}$ and $\bar{e}_{B 2}$ that are less stringent than the laissez-faire emissions and are therefore reached via emission subsidies.

Policy III: $\pi_{A 1}=\pi_{B 1} \neq 0, \pi_{A 2}=\pi_{B 2} \neq 0, p_{e}=\mu_{e}-\pi_{A 2} \geq 0$ and $\pi_{A 1}=\bar{\mu}+\pi_{A 2}$. The countries $A$ and $B$ implement caps in both periods. These mixed policies may exhibit negative emission prices only ( $=$ emission subsidies; $0>\pi_{A 1}>\pi_{A 2}$ ), mixed negative and positive emission prices $\left(\pi_{A 1}>0>\pi_{A 2}\right)$ or cap and trade schemes in the narrow sense $\left(\pi_{A 1}>0, \pi_{A 2}>0\right)$.

Multiple sets of equilibrium prices exist, because according to (6) $p_{e}$ and $\pi_{i t}$ for $t=1,2$ impact on the profits $\Pi^{i}$ in country $i=A, B$ only through the firms' unit costs of fossil fuel, $p_{e}+\pi_{i t}$. Therefore, the level of emission prices can be shifted up or down without changing the equilibrium allocation as long as that shift is exactly compensated by a shift in opposite direction of the fossil fuel price $p_{e}$.

The common feature of the Policies I, II and III is the minimization of the overall (welfare) cost of implementing $\bar{e}_{1}$. Yet the countries' shares of the burden differ across these policies because changes in the world market price of fossil fuel, $p_{e}$, change fuel export 
revenues and fuel import expenditures. Assuming that appropriate lumpsum side payments secure the countries' cooperation, we will disregard this kind of distributional issues in the sequel. Another common feature of all policies in Proposition 1 is that both countries credibly commit to the (joint) policy chosen as a precondition for the fossil-fuel extracting firm to follow the Hotelling rule. That is clearly a very restrictive assumption which is arguably more 'heroic' for the Policies II and III than for Policy I because a commitment to regulation in the far future likely is less credible than a commitment to taxes in the near future. (See also footnote 5.)

As to the allocative implications of Policy I listed in Proposition 1(b), it is clear, of course, that the caps $\bar{e}_{A 1}$ and $\bar{e}_{B 1}$ of that policy satisfy $\bar{e}_{A 1}+\bar{e}_{B 1}=\bar{e}_{1}$. But they must also be fixed such that the production conditions (17) and (18) are met. Hence if each country runs its own domestic cap and trade scheme, the national regulator would need full information on technologies in both countries to fix the appropriate cap $\bar{e}_{A 1}$ and $\bar{e}_{B 1}$, respectively. The informational requirements are much lower, if countries operate a joint first-period cap- and -trade scheme with the total amount of permits issued being $\bar{e}_{1}$. Such a scheme would also be cost effective and would allow for varying the national permit endowments $\bar{e}_{A 1}$ and $\bar{e}_{B 1}$ subject to $\bar{e}_{A 1}+\bar{e}_{B 1}=\bar{e}_{1}$ for the purpose of changing the distribution of national incomes.

To assess the allocative displacement effects of Policy I suppose temporarily that the cap $\bar{e}_{1}$ is so large that the constraint $e_{1} \leq \bar{e}_{1}$ is not binding in the solution of (13). With $\bar{\mu}=0$, the equations (17) and (18) characterize a Pareto efficient allocation which requires (i) that the marginal productivity of good $X$ is the same across countries and periods (production efficiency), (ii) that the marginal willingness-to-pay for consumption in period 2 (in terms of first-period consumption) is the same in both countries (consumption efficiency) and (iii) that the marginal willingness to pay for consumption in period 2 equals marginal costs (overall efficiency). With $\bar{\mu}=0$, (17) represents the conditions (i) and (ii) and (18) establishes condition (iii). With that efficiency benchmark in mind, reconsider Policy I that is characterized by $\bar{\mu}>0$. In Policy I production efficiency is obviously violated, because (17) now shows that marginal productivities differ across periods. The positive emission price $\pi_{A 1}=\pi_{B 1}$ drives a wedge between the marginal willingness to pay for and the marginal cost of second-period consumption.

Compare finally the prices $p_{e}$ and $p_{x}$ under Policy I with the prices $p_{e}^{o}$ and $p_{x}^{o}$ in laissez-faire equilibrium. Since $\pi_{A 1}=\pi_{B 1}=\pi_{1}>0, p_{e}+\pi_{1}$ must be greater than $p_{e}^{o}$ because otherwise total first-period production would not be reduced. Moreover, stimulation of production in period 2 requires $\left(p_{e} / p_{x}\right)<\left(p_{e}^{o} / p_{x}^{o}\right)$, while $p_{x}<p_{x}^{o}$ is necessary to shift part of the consumers' consumption from the first to the second period for adjustment of demand to the changes in supply of good $X$ in both periods. Obviously, both inequalities can only 
be satisfied through a pronounced drop in the fossil fuel price (below $p_{e}^{o}$ ).

\section{Unilateral climate stabilization}

Suppose now, the cooperative solution characterized in the previous section cannot be attained because country $B$ abstains from emission regulation while country $A$ is willing to stabilize the climate unilaterally. Given our stylized climate scenario (Section 2), country $A$ knows that business as usual destabilizes the climate and that taking unilateral action is not only costly but also futile, if that action does not prevent first-period emissions $e_{1}$ from exceeding the carbon budget $\bar{e}_{1}$. Hence country $A$ makes use of its policy instruments $\left(\bar{e}_{A 1}, \bar{e}_{A 2}, \tau_{A 1}=\tau\right)$ to implement the carbon budget $\bar{e}_{1}$ taking into account that country $B$ proceeds with business as usual. In Section 4.1 we aim to specify some policies $\left(\bar{e}_{A 1}, \bar{e}_{A 2}, \tau\right)$ which succeed in bringing down $e_{1}$ from $e_{1}^{o}$ to $\bar{e}_{1}$. In Section 4.2 we analyze unilateral carbon budget policies that are cost effective for country $A$.

\subsection{Feasible policies for unilateral climate stabilization}

To avoid clumpsy wording we denote as $\bar{e}_{1}$-policies of country $A$ all mixed policies $\left(\bar{e}_{A 1}, \bar{e}_{A 2}, \tau\right)$ that implement the carbon budget $\bar{e}_{1}<e_{1}^{o}$. We assume that country $A$ has at its disposal such an $\bar{e}_{1}$-policy. That assumption is clearly satisfied, if country $A$ is large (or 'rich') enough relative to country $B$ and if the required total emission reduction, $e_{1}^{o}-\bar{e}_{1}$, is not too large. It is important to know whether country $A$ can choose among different $\bar{e}_{1}$-policies because that is a precondition for the opportunity - and challenge - to select that particular $\bar{e}_{1}$-policy which complies with the carbon budget at least cost for country $A$. Proposition 2 (below) establishes that if country $A$ is capable to carry out a unilateral carbon budget policy the use of its consumption tax instrument opens up the choice among a variety of feasible $\bar{e}_{1}$-policies.

Proposition 2. Suppose the utility functions are CES,

$$
U\left(x_{i 1}, x_{i 2}\right)=\left(\gamma_{1} x_{i 1}^{\frac{\sigma_{i}-1}{\sigma_{i}}}+\gamma_{2} x_{i 2}^{\frac{\sigma_{i}-1}{\sigma_{i}}}\right)^{\frac{h \sigma_{i}}{\sigma_{i}-1}} \quad \text { for } i=A, B
$$

with $\gamma_{1}, \gamma_{2}, h>0$ and $\sigma_{A}=\sigma_{B} \equiv \sigma>0, \sigma \neq 1$. For every $\left(\bar{e}_{A 1}, \bar{e}_{A 2}\right) \in\left[0, \bar{e}_{1}\right] \times\left[0, \bar{e}_{2}\right]$ there exists a set $S \in \mathbb{R}_{++}$with non-empty interior and $\tau \in \mathbb{R}$ such that the policy $\left(\bar{e}_{A 1}, \bar{e}_{A 2}, \tau\right)$ is an $\bar{e}_{1}$-policy in all economies characterized by $\sigma \in S$.

Proposition 2 clarifies that whether or not $\bar{e}_{1}$ can be implemented by some given caps $\left(\bar{e}_{A 1}, \bar{e}_{A 2}\right) \in\left[0, \bar{e}_{1}\right] \times\left[0, \bar{e}_{2}\right]$ depends on the size of the elasticity of substitution in demand, 
$\sigma$, and on an approriate level of the tax rate $\tau$. The proof of Proposition 2 in the Appendix A highlights the role of the consumption tax $\tau$ in subglobal $\bar{e}_{1}$-policies. To further clarify the relevance of the consumption tax as a regulatory device in such policies we find it useful to consider a specific feasible $\bar{e}_{1}$-policy and compare it with the laissez-faire equilibrium $E^{o}$ in $^{11}$

Proposition 3. Suppose the countries $A$ and $B$ are identical and their utility functions are CES. If country A keeps its laissez-faire emissions unchanged, $\bar{e}_{A t}=e_{A t}^{o}$ for $t=1,2$, there exists $\tilde{\tau}>0$ such that $\left(\bar{e}_{A 1}=e_{A 1}^{o}, \bar{e}_{A 2}=e_{A 2}^{o}, \tilde{\tau}\right)$ is an $\bar{e}_{1}$-policy. The resultant equilibrium is characterized by $\pi_{A 1}<0, \pi_{A 2}>0, p_{e}>p_{e}^{o}, p_{x}>p_{x}^{o}$.

The remarkable feature of policy $\left(e_{A 1}^{o}, e_{A 2}^{o}, \tilde{\tau}\right)$ of Proposition 3 is that country $A$ leaves its first and second-period emissions at their laissez-faire levels. As a consequence, the burden of reducing first-period emissions from $e_{1}^{o}$ to $\bar{e}_{1}$ is entirely on country $B(!) .{ }^{12}$ Country $A$ induces country $B$ to reduce its first-period emissions by raising $p_{e}$. If $p_{e}$ goes up, $p_{x}$ must increase as well, because the necessary expansion of country $B$ 's second-period production requires the price ratio $\left(p_{e} / p_{x}\right)$ to decline. The rise in $p_{x}$ shifts (some) consumption from the second to the first period which would create an excess demand for consumption in period 1 , ceteris paribus. To prevent that from happening, country $A$ makes use of the consumption tax. The rationale of $\tilde{\tau}>0$ is to discourage first-period consumption in country $A$ or, in other words, to shift some of country $A$ 's consumption (back) from the first to the second period. In that way an equilibrium on the first- and second-period (world) market for good $X$ is secured. The policy $\left(e_{A 1}^{o}, e_{A 2}^{o}, \tilde{\tau}\right)$ of Proposition 3 differs markedly from the cost-effective cooperative policy regarding the fossil fuel price: $p_{e}>p_{e}^{o}$ results from the former policy but $p_{e}<p_{e}^{o}$ from the latter. Note also that keeping the emissions $e_{A 1}$ and $e_{A 2}$ constant at their laissez-faire levels does not imply that these emission caps are unpriced. On the contrary, it is necessary to subsidize first-period emissions $\left(\pi_{A 1}<0\right)$ and to tax second-period emissions $\left(\pi_{A 2}>0\right)$.

\subsection{Cost-effective unilateral climate stabilization}

\subsubsection{The analytical approach}

The previous section offered insights into the patterns of mixed $\bar{e}_{1}$-policies $\left(\bar{e}_{A 1}, \bar{e}_{A 2}, \tau\right)$ which country $A$ has at its disposal. As compared to laissez faire, country $A$ 's unilateral action

\footnotetext{
${ }^{11}$ The proof of Proposition 3 is delegated to the Appendix B.

${ }^{12}$ Nonetheless, country $B$ is shown (see the Appendix B) to gain unambiguously and country $B$ loses from country $A$ 's unilateral climate stabilization via policy $\left(e_{A 1}^{o}, e_{A 2}^{o}, \tilde{\tau}\right)$.
} 
causes allocative distortions which, in turn, change the welfare of both countries and, in general, translate into a welfare loss for country $A$. That welfare loss represents country $A$ 's cost of (unilateral) climate stabilization and depends on the particular policy chosen. Hence it is in country $A$ 's interest to select the least-cost policy among all feasible $\bar{e}_{1}$-policies $\left(\bar{e}_{A 1}, \bar{e}_{A 2}, \tau\right)$.

To characterize the unilateral $\bar{e}_{1}$-policy that is cost effective for country $A$ we envisage a regulator who maximizes the utility of the consumer in country $A$ through an appropriate choice of her policy instruments ${ }^{13} \bar{e}_{A 1}$ and $\bar{e}_{A 2}$. In her optimization procedure the regulator takes into account

- the equilibrium conditions (3) for the commodity markets,

- the fuel/emission constraints

$$
\bar{e}_{A 1}+e_{B 1}=\bar{e}_{1} \quad \text { and } \quad \bar{e}_{A 2}+e_{B 2}=\bar{e}_{2}:=\bar{e}-\bar{e}_{1}
$$

(where the equality signs are assumed to hold ${ }^{14}$ ),

- the input demand and output supply functions of all producers

- and the consumption demand functions of the consumer in country $B$.

We proceed by demonstrating in several steps that under the constraints listed here the utility of the consumer in country $A$ is, in fact, completely determined by the policy parameters $\bar{e}_{A 1}$ and $\bar{e}_{A 2}$.

The supply side partial equilibrium. Consider $^{15}(20)$ and the first-order conditions of profit maximization

$$
\begin{aligned}
X_{e_{A 1}}^{A}\left(e_{A 1}\right) & =p_{e}+\pi_{A 1}, \\
X_{e_{B 1}}^{B}\left(\bar{e}_{1}-e_{A 1}\right) & =p_{e}, \\
p_{x} X_{e_{A 2}}^{A}\left(e_{A 2}\right) & =p_{e}+\pi_{A 2}, \\
p_{x} X_{e_{B 2}}^{B}\left(\bar{e}_{2}-e_{A 2}\right) & =p_{e} .
\end{aligned}
$$

These equations determine the supply-side system of the competitive economy for all $\left(e_{A 1}\right.$, $\left.e_{A 2}\right) \in\left[0, \bar{e}_{1}\right] \times\left[0, \bar{e}_{2}\right]$. They ensure an equilibrium of the fossil fuel markets in both periods and determine $p_{e}, p_{x}, \pi_{A 1}, \pi_{A 2}$ and $x_{i t}^{s}$ for $i=A, B$ and $t=1,2$ for every $\left(e_{A 1}, e_{A 2}\right) \in$ $\left[0, \bar{e}_{1}\right] \times\left[0, \bar{e}_{2}\right]$.

\footnotetext{
${ }^{13}$ The consumption tax is no ingredient of the regulator's optimization problem but is rather implied by its solution. This will be made precise below.

${ }^{14}$ The consequence of the equalities (20) is that emission prices $\pi_{A 1}, \pi_{A 2}$ may turn out to be negative.

${ }^{15}$ See also the proof of Proposition 2 in Appendix A.
} 
The consumer in country $B$. In order to investigate in detail the impact on results of the elasticity of intertemporal substitution in consumption, $\sigma$, we simplify the exposition by resorting to the CES utility function (19). The consumer in country $B$ maximizes her utility subject to the budget constraint

$$
x_{B 1}+p_{x} x_{B 2}=X\left(e_{B 1}\right)+p_{x} X\left(e_{B 2}\right)+p_{e}\left(\alpha_{B} \bar{e}-e_{B 1}-e_{B 2}\right)=: y_{B} .
$$

The resulting consumption is

$$
x_{B 1}=\frac{\bar{\gamma} p_{x}^{\sigma_{B}} y_{B}}{p_{x}+\bar{\gamma} p_{x}^{\sigma_{B}}}=: B^{1}\left(e_{A 1}, e_{A 2}\right) \quad \text { and } \quad x_{B 2}=\frac{y_{B}}{p_{x}+\bar{\gamma} p_{x}^{\sigma}}=: B^{2}\left(e_{A 1}, e_{A 2}\right),
$$

where $\bar{\gamma}:=\left(\frac{\gamma_{1}}{\gamma_{2}}\right)^{\sigma_{B}}$ and where it follows from (20), (22), (24) and (25) that the consumption $\left(x_{B 1}, x_{B 2}\right)$ in $(26)$ is uniquely determined by $\left(e_{A 1}, e_{A 2}\right)$.

Cost-effective regulation. The regulator of country $A$ realizes that under consideration of (1), (20) and (26) the consumption $x_{A t}(t=1,2)$ from (3) turns into

$$
x_{A t}=A^{t}\left(e_{A 1}, e_{A 2}\right):=X\left(e_{A t}\right)+X\left(\bar{e}_{1}-e_{A t}\right)-B^{t}\left(e_{A 1}, e_{A 2}\right) \quad \text { for } t=1,2 .
$$

She then maximizes $U^{A}\left[A^{1}\left(e_{A 1}, e_{A 2}\right), A^{2}\left(e_{A 1}, e_{A 2}\right)\right]$ over $\left[0, \bar{e}_{1}\right] \times\left[0, \bar{e}_{2}\right]$ which yields the firstorder conditions

$$
\frac{U_{x_{A 2}}^{A}}{U_{x_{A 1}}^{A}}=-\frac{A_{e_{A 1}}^{1}}{A_{e_{A 1}}^{2}}=-\frac{A_{e_{A 2}}^{1}}{A_{e_{A 2}}^{2}} .
$$

In the competitive economy with consumption $\operatorname{tax} \tau$ the consumer price of first-period consumption in country $A$ is $1+\tau$. When the consumer of country $A$ maximizes her utility (taking prices and income as given) the corresponding first-order condition reads $\frac{U_{x_{A 2}}^{A}}{U_{x_{A 1}}^{A}}=\frac{p_{x}}{1+\tau}$ which gives rise to the equivalence

$$
\frac{U_{x_{A 2}}^{A}}{U_{x_{A 1}}^{A}} \gtreqless p_{x} \quad \Longleftrightarrow \quad \tau \lesseqgtr 0 .
$$

The information contained in (25) through (29) yields

Proposition 4. Suppose country B's utility function is CES, country B abstains from carbon emission regulation and country A pursues a unilateral cost-effective $\bar{e}_{1}$-policy $\left(\bar{e}_{A 1}, \bar{e}_{A 2}, \tau\right)$. That policy is characterized as follows:

(a) $\Delta e_{A}>0 \Longrightarrow \pi_{A t}<0$ for $t=1,2$ or $\pi_{A 1} \cdot \pi_{A 2} \leq 0$, where $\Delta e_{A}:=\alpha_{A} \bar{e}-e_{A 1}-e_{A 2}$.

(b) $\Delta e_{A}<0 \Longrightarrow \pi_{A t}>0$ for $t=1,2$ or $\pi_{A 1} \cdot \pi_{A 2} \leq 0$.

(c) If $\sigma_{B} \geq 1$, then $\tau \gtreqless 0 \Longleftrightarrow-\Delta x_{B 1} \lesseqgtr-\pi_{A 1} e_{B 1} \eta_{B 1} \Longleftrightarrow p_{x} \Delta x_{B 2} \lesseqgtr \pi_{A 2} e_{B 2} \eta_{B 2}$, where $\Delta x_{B t}:=x_{B t}^{s}-x_{B t}$ and $\eta_{B t}:=X_{e_{B t}} /\left(e_{B t} X_{e_{B t} e_{B t}}\right)$ for $t=1,2$. 
Proposition 4 demonstrates that the specific features of country $A$ 's cost-effective $\bar{e}_{1}$-policy heavily depend on the patterns of export and import $\left(\Delta e_{A}, \Delta x_{B 1}, \Delta x_{B 2}\right)$. Yet on the whole Proposition 4 is disappointing because it provides very limited information only on the analytical characteristics of unilateral cost-effective $\bar{e}_{1}$-policies. It is not even possible to extract from the optimality conditions meaningful sufficient conditions for $\tau \neq 0$ or for $\bar{e}_{A t} \neq e_{A t}^{o}, t=1,2$. To make progress we consider next the polar case ${ }^{16}$ of identical utility functions in both countries with $\sigma=\infty$.

If $\sigma=\infty$, the indifference curves are downward sloping straight lines. Therefore there is only one price $p_{x}$, say $\breve{p}_{x}$, at which a laissez-faire equilibrium exists, because the consumer's budget line must have the same slope as the indifference line. Obviously, the consumer is then indifferent between all points on her budget line such that the equilibrium consumption is determined by the supply side. The immediate consequences are (i) that $\tau=0$ is a necessary condition for all $\bar{e}_{1}$-policies and (ii) that country $i$ 's income $y_{i}, i=A, B$, is strictly increasing in its consumer's utility. Therefore country $A$ 's cost-effective policy is the solution of

$$
\max _{e_{A 1} \in\left[0, \bar{e}_{1}\right]} y_{A}:=X\left(e_{A 1}\right)+\breve{p}_{x} X\left(e_{A 2}\right)+p_{e}\left(\alpha_{A} \bar{e}-e_{A 1}-e_{A 2}\right)
$$

s.t. $e_{A 1}+e_{B 1}=\bar{e}_{1}$ and $p_{e}=X_{e_{B 1}}=X_{e_{A 1}}=\breve{p}_{x} X_{e_{A 2}}$. Solving (30) and making use of $\frac{\mathrm{d} p_{e}}{\mathrm{~d} e_{A 1}}=-\frac{1}{X_{e_{B 1} e_{B 1}}}>0$ yields, after rearrangement of terms,

and hence

$$
\frac{\mathrm{d} y_{A}}{\mathrm{~d} e_{A 1}}=-\frac{\Delta e_{A}}{X_{e_{B 1} e_{B 1}}}
$$

$$
\Delta e_{A}\left\{\begin{array}{l}
> \\
= \\
<
\end{array}\right\} 0 \Longleftrightarrow \bar{e}_{A 1}\left\{\begin{array}{l}
=\bar{e}_{1}, \\
\in\left[0, \bar{e}_{1}\right], \\
=0 .
\end{array}\right.
$$

We have thus demonstrated that for $\sigma=\infty$ country $A$ 's cost-effective policy depends on whether it exports or imports fossil fuel in an extremely sensitive way. While $\sigma=\infty$ is clearly an unrealistic assumption that polar case reveals, nonetheless, a more general (though less extreme) feature of country $A$ 's effort to keep its welfare loss as small as possible. Country $A$ chooses its policy instruments as to change the terms of trade. In all cases $\sigma \leq \infty$ country $A$ determines also $p_{x}$ via choice of $\bar{e}_{A 1}$ and $\bar{e}_{A 2}$.

Although these observations shed more light on country $A$ 's cost-effective $\bar{e}_{1}$-policy, the first- and second-order equilibrium effects of variations in policy instruments are still to complex to allow for an informative characterization of that policy. The following numerical calculations promise additional insights.

\footnotetext{
${ }^{16}$ Interestingly, for the other polar case, $\sigma=0$, unilateral carbon budget policies are unfeasible because no equilibrium exists.
} 


\subsubsection{Numerical examples}

We simplify by assuming that production functions and utility functions are the same across countries and time. The functional forms of utility and production are

$$
U\left(x_{i 1}, x_{i 2}\right)=x_{i 1}^{\gamma} x_{i 2}^{1-\gamma} \quad \text { and } \quad X^{i}\left(e_{i t}\right)=a e_{i t}-\frac{b}{2} e_{i t}^{2} \quad \text { for } i=A, B ; t=1,2,
$$

and we choose the parameter values $a=1, b=0.1, \bar{e}=2, \bar{e}_{1}=1$ and $\gamma=0.7$. We fix $\left.\alpha_{A}=\left(1-\alpha_{B}\right) \in\right] 0,1[$, country $A$ 's share of the total stock of fossil fuel, alternatively at $\alpha_{A}=0.5$ (Example 1) and at $\alpha_{A}=1$ (Example 2). Table 1 summarizes the results.

\begin{tabular}{|l||c|c|c||c|c|r|}
\hline \multicolumn{1}{|c||}{} & \multicolumn{3}{c||}{ Example 1 $\left(\alpha_{A}=0.5\right)$} & \multicolumn{3}{c|}{ Example 2 $\left(\alpha_{A}=1\right)$} \\
& Laissez faire & Regulation & R minus L & Laissez faire & Regulation & R minus L \\
\hline \hline$e_{A 1}$ & 0.695 & 0.385 & -0.310 & 0.695 & 0.646 & -0.049 \\
\hline$\pi_{A 1}$ & 0 & 0.023 & +0.023 & 0 & -0.029 & -0.029 \\
\hline$e_{A 2}$ & 0.304 & 0.775 & +0.471 & 0.304 & 0.745 & +0.441 \\
\hline$\pi_{A 2}$ & 0 & -0.050 & -0.050 & 0 & -0.050 & -0.050 \\
\hline$e_{B 1}$ & 0.695 & 0.615 & -0.080 & 0.695 & 0.354 & -0.341 \\
\hline$e_{B 2}$ & 0.304 & 0.225 & -0.079 & 0.304 & 0.255 & -0.049 \\
\hline$\left.\Delta_{e_{A}}{ }^{a}\right)$ & 0 & -0.160 & -0.160 & 1 & 0.609 & -0.391 \\
\hline$p_{x}$ & 0.959 & 0.960 & +0.001 & 0.959 & 0.990 & +0.031 \\
\hline$p_{e}$ & 0.930 & 0.940 & +0.010 & 0.930 & 0.970 & +0.040 \\
\hline$\tau$ & 0 & 3.790 & +3.790 & 0 & 1.320 & +1.320 \\
\hline$\Delta x_{A 1} b^{\prime}$ & 0 & 0.075 & +0.075 & -0.651 & -0.341 & +0.310 \\
\hline$\Delta x_{A 2}$ & 0 & 0.077 & +0.077 & -0.291 & -0.249 & +0.042 \\
\hline$x_{A 1} / x_{A 2}$ & 2.239 & 0.450 & -1.789 & 2.239 & 1.000 & -1.239 \\
\hline$x_{B 1} / x_{B 2}$ & 2.239 & 2.240 & +0.001 & 2.239 & 2.309 & +0.070 \\
\hline$x_{1} / x_{2}$ & 2.239 & 1.007 & -1.232 & 2.239 & 1.004 & -1.235 \\
\hline$u_{A}$ & 0.527 & 0.383 & -0.144 & 1.038 & 1.031 & -0.007 \\
\hline$u_{B}$ & 0.527 & 0.5274 & +0.0004 & 0.016 & 0.005 & -0.011 \\
\hline
\end{tabular}

$$
{ }^{a)} \Delta e_{A}=\alpha_{A} \bar{e}-e_{A 1}-e_{A 2}=-\Delta e_{B},{ }^{b)} \Delta x_{A t}=-\Delta x_{B t}
$$

Table 1: Two examples of unilateral cost-effective regulation

In our subsequent comments on Table 1 we wish to highlight the main features of both examples compared to the laissez-faire case (absence of regulation), but also similarities and differences between both examples as well as between the examples and the cost-effective global carbon budget policy (Section 3). 
To begin with, observe that the laissez-faire equilibrium of Example 1 is symmetric, because no regulation takes place and the countries are alike. From Table 1 we calculate $e_{A 1}^{o}+e_{B 1}^{o}=: e_{1}^{o}=1.39$, while the first-period emission cap $\bar{e}_{1}$ is assumed to be $\bar{e}_{1}=1.00$. That constitutes a cut of total laissez-faire first-period emissions of about $28 \%$. The results are surprising. In period 1 country $A$ reduces its own emissions drastically, supported by a positive price for emisions $\left(\pi_{A 1}=0.023\right)$, but it expands its own second-period emissions even more drastically, accomplished by means of a subsidy on its second-period emissions $\left(\pi_{A 2}=-0.05\right)$. That feature of country A's cost-effective policy contrasts strongly with the cooperative cost-effective regulation (Proposition 1, Policy I) that leaves period 2 totally unregulated.

With $\tau=0$ the policy $\left(e_{A 1}=0.385, e_{A 2}=0.775\right)$ of Example 1 would result in an excess demand [supply] of good $X$ in the first [second] period. That disequilibrium is avoided through raising $\tau$ to the value $\tau=3.79$ (see also the proof of Proposition 2 in the Appendix A). Comparing the low (absolute) values of $\pi_{A 1}$ and $\pi_{A 2}$ with $\tau=3.79$ suggests that a major share of regulatory burden rests with the tax on consumption. That observation is confirmed by the fact that both prices, $p_{e}$ and $p_{x}$, slightly increase rather than decline as they would need to in absence of the consumption tax. The increase in $p_{e}$ and $p_{x}$ is also in stark contrast to the cooperative cost-effective regulation (Proposition 1) and it is at variance with the conventional understanding that emission reductions in some parts of the world would tend to 'expropriate' fossil fuel owners. Another remarkable feature of regulation in Example 1 is that, with the laissez-faire equilibrium as the benchmark, country $B$ reduces its emissions in both periods. Thus somewhat ironically, country $A$ stabilizes the climate by inducing country $B$ to reduce emissions while its overall emissions expand (from $e_{A}^{o}=e_{A 1}^{o}+e_{A 2}^{o}=1$ to $\left.e_{A}=1.16\right)$.

Having acknowledged the fundamental difference in policy design between unilateral global and subglobal carbon-budget policy, in its essence country A's subglobal policy is similar in spirit to the global policy, nonetheless. Both first-period instruments of country $A, e_{A 1}<e_{A 1}^{o}$ and $\tau>0$, work towards shifting fuel consumption into period 2 and so does the 'cap' $e_{A 2}>e_{A 2}^{o}$. However, a side-effect of expanding $e_{A 2}$ is that the price $p_{x}$ of secondperiod consumption rises (slightly) which creates an incentive to increase consumption in period 1. Country $A$ must tolerate that increase in country $B$, but prevents it at home by raising $\tau$.

Consider next country $A$ 's cost-effective policy in Example 2 and recall that both economies differ only in their shares of the total stock of fossil fuel $\left(\alpha_{A}=\alpha_{B}=0.5\right.$ in Example 1 versus $\alpha_{A}=1$ and $\alpha_{B}=0$ in Example 2). In laissez-faire equilibrium the production allocation and prices $p_{e}$ and $p_{x}$ are the same in both economies, but country $A$ 's 
first and second-period consumption is higher in Example 2 because by assumption country $A$ is richer in Example 2 than in Example 1. The comparison of the pattern of unilateral regulation in both economies reveals remarkable similarities and differences: In Example 2

- the cosumption tax is positive as in Example 1 though the tax rate is lower;

- the cap $e_{A 2}$ and the corresponding emission price $\pi_{A 2}<0$ are about the same as in Example 1;

- the cap $e_{A 1}$ is substantially les stringent than in Example 1 implying, as to be expected, that the emission price $\pi_{A 1}$ is smaller $\left(\pi_{A 1}<0\right.$, in fact $)$ than in Example 1 ;

- country A's aggregate first and second-period emissions are larger than in Example 1 (where they have already been larger than in laissez-faire); thus in Example 2 country $B$ is also the 'true abating country', and even more so than in Example 1;

- the prices $p_{e}$ and $p_{x}$ are higher than the laissez-faire prices but that increase is slightly more pronounced than in Example 1.

A remarkable feature of regulation in Example 2 is that country $A$ 's reduction of first-period emissions which amounts to about $7 \%$ of laissez-faire emissions is implemented by a subsidy $\left(\pi_{A 1}<0\right)$ rather than a tax. Taking the laissez-faire equilibrium as the baseline, country $B$ loses out in both periods in production as well as consumption and hence suffers a welfare loss. Thus in Example 2 country $A$ is able to shift some share of the climate stabilization burden on country $B$. In Example 1 country $B$ benefits, though only slightly, which suggests that country $A$ succeeds in spoiling country $B$ 's free rider position.

We have run several more simulations with different functional forms not reported here which showed that the results of Examples 1 and 2 appear to be fairly robust. We take this as an indication that unilateral cost-effective $\bar{e}_{1}$-policies may exhibit some general characteristics. More specifically, our numerical calculations suggest to ask the questions, whether it is a common feature of such policies that

(i) $\bar{e}_{A 2}>e_{A 2}^{o}$ and $\pi_{A 2}<0$;

(ii) $\tau>0$;

(iii) $e_{B 1}<e_{B 1}^{o}, e_{B 2}<e_{B 2}^{o}$ and $\left(\bar{e}_{A 1}+\bar{e}_{A 2}\right)>\left(e_{A 1}^{o}+e_{A 2}^{o}\right)$;

(iv) $p_{e}>p_{e}^{o}$ and $p_{x}>p_{x}^{o}$.

Unforunately, answers to those questions will likely remain conjectures because general results based on rigorous analysis are not available. 


\subsubsection{An illustration of Example 1}

Figure 1 illustrates the economy of Example 1 depicting the supply side of both the laissezfaire equilibrium and the equilibrium under country $A$ 's cost-effective $\bar{e}_{1}$-policy. In the absence of regulation, the straight lines $D_{A 1}^{o}, D_{B 1}^{o}, D_{A 2}^{o}$ and $D_{B 2}^{o}$ are the graphs of the individual countries' demand functions for fossil fuel in period 1 and period 2, respectively, and they are also the graphs of the supply functions for emissions. The demand curves $D_{A 2}^{o}$ and $D_{B 2}^{o}$ can be drawn only for some predetermind price $p_{x}$, say $p_{x}^{o}$, which we take to be the price prevailing in laissez-faire equilibrium. In the middle panel of Figure 1 the lines $D_{1}^{o}$ and $D_{2}^{o}$ represent the aggregate fuel demand curves of the periods 1 and 2, respectively. Their point of intersection, $E^{o}$, marks the laissez-faire equilibria on the markets for fossil fuel as well as the equilibrium fuel price in both periods.

Once we have established the laissez-faire equilibrium as a benchmark, we are ready to illustrate country $A$ 's cost-effective policy by introducing the cap $\bar{e}_{A 1}<e_{A 1}^{o}$ in the far left panel and $\bar{e}_{A 2}>e_{A 2}^{o}$ in the far right panel of Figure 1. Those caps turn the demand functions $D_{A 1}^{o}$ and $D_{A 2}^{o}$ into the vertical straight lines $D_{A 1}^{r}$ and $D_{A 2}^{r}$, respectively. As we know from Table $1, p_{x}^{r}$ is greater than $p_{x}^{o}$ which shifts the demand function $D_{B 2}^{o}$ upward (as well as the unconstrained second-period demand function of country $A$ ). The new aggregate demand functions are $D_{1}^{r}$ and $D_{2}^{r}$ in the middle panel of Figure 1 and their point of intersection marks the equilibrium of the fossil fuel markets of both periods. The new equilibrium price of fossil fuel is $p_{e}^{r}>p_{e}^{o}$. The far left [right] panel shows that at $p_{e}=p_{e}^{r}$ country $A^{\prime}$ 's fuel demand exceeds $\bar{e}_{A 1}$ [falls short of $\bar{e}_{A 2}$ ] such that an emission price $\pi_{A 1}^{r}>0\left[\pi_{A 2}^{r}<0\right.$ ] is necessary to secure $e_{A 1}=\bar{e}_{A 1}\left[e_{A 2}=\bar{e}_{A 2}\right]$. Country $B$ responds to the fall of $p_{e}$ by reducing $e_{B 1}$ and (in Figure 1$)^{17}$ by expanding $e_{B 2}$.

\footnotetext{
${ }^{17} e_{B 2}^{r}>e_{B 2}^{o}$ is the only qualitative deviation from Example 1 in Table 1. Figure 1 is a free-hand drawing and the 'mistake' is deliberate for the benefit of better exposition.
} 


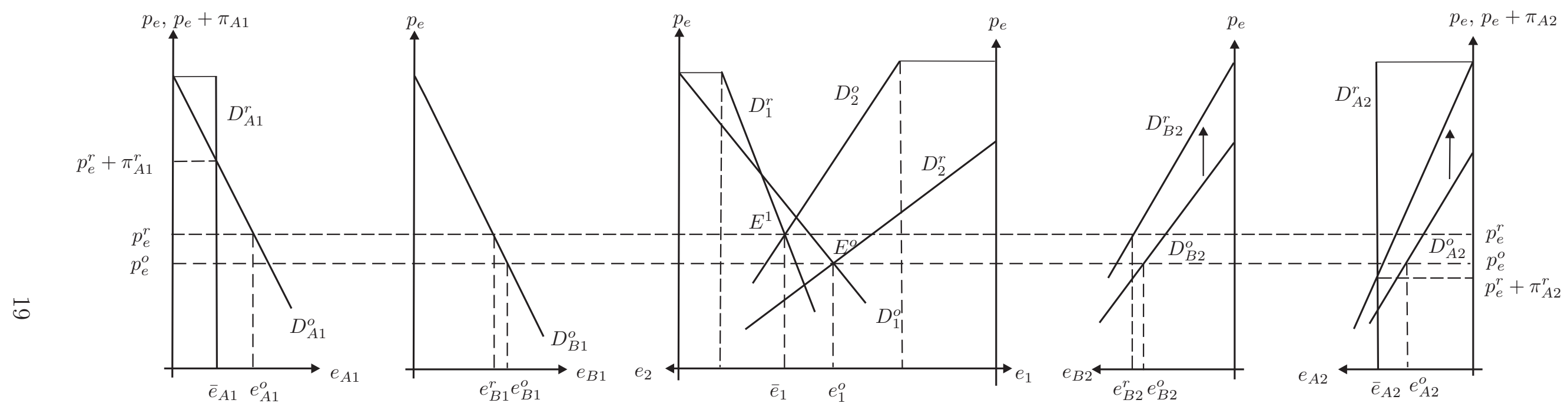

Figure 1: Unilateral cost-effective regulation of country $A$ (Example 1) 
To sum up, in Figure 1 the following variables in the equilibrium with country $A$ 's emission caps $\left(\bar{e}_{A 1}, \bar{e}_{A 2}\right)$ are fixed: $p_{e}^{r}, \pi_{A 1}^{r}, \pi_{A 2}^{r}, e_{B 1}^{r}$ and $e_{B 2}^{r}$. Thus the production of the consumption good is fully determined in both countries and periods while the demand for good $X$ is not at all captured in Figure 1. We need to demonstrate, with arguments beyond Figure 1, what the mechanism is that equilibrates the markets for good $X$ in both periods. To this end observe first that according to Table $1\left(x_{B 1}^{r} / x_{B 2}^{r}\right)>\left(x_{B 1}^{o} / x_{B 2}^{o}\right)$. For $\tau=0$ that inequality would also hold for country $A$. Given identical Cobb-Douglas utility functions (that are homothetic functions), $\tau=0$ would clearly result in an excess demand [supply] in the first-period [second-period] market of good $X$ because $\left(x_{A 1}^{r}+x_{B 1}^{r}\right) /\left(x_{A 2}^{r}+x_{B 2}^{r}\right)$ $<\left(x_{A 1}^{o}+x_{B 1}^{o}\right) /\left(x_{A 2}^{o}+x_{B 2}^{o}\right)$. To avoid these commodity-market disequilibria country $A$ needs to levy the first-period consumption tax in order to shift part of country $A$ 's first-period demand for good $X$ to the second period. ${ }^{18}$

\section{Concluding remarks}

Although there is no ultimate scientific evidence for a knife-edge temperature rise of $2^{\circ} \mathrm{C}$ that separates stable from chaotic, irreversible and uncontrollable climate, this knife-edge temperature limit is consensus among many experts. Even all 16 leading economies and the European Union (G8 and MEF countries), which are responsible for about $80 \%$ of global greenhouse gas emissions, acknowledged at the meeting in L'Aquila in July 2009 for the first time the importance of limiting global warming to $2^{\circ} \mathrm{C}$. There is a realistic chance of restricting global warming to $2^{\circ} \mathrm{C}$ if a limit is set on the total amount of $\mathrm{CO}_{2}$ emitted globally between now and 2050 (global carbon budget).

From today's perspective it is not clear whether the global carbon budget will be reached at all, whether it will be observed by a global climate coalition or whether a subglobal climate coalition will prevent global emissions from exceeding the carbon budget. However, the potential for free-riding is a severe obstacle to cooperation. Countries which do not join the climate coalition can enjoy the benefits of climate stabilization without bearing the costs. Since some countries already have a national emission cap, the most likely candidate for maintaining the global carbon budget is a subglobal climate coalition. The present paper characterizes the cost-effective policy of a subglobal climate coalition and compares that regulation with the global cost-effective solution. In the benchmark scenario of cost-effective global carbon policy a global first-period cap and trade scheme implements the carbon budget. The cost-effective subglobal carbon budget policy is shown to differ markedly from the cost-effective global carbon budget policy and exhibits a number of unexpected features.

\footnotetext{
${ }^{18}$ See also the proof of Proposition 2 in the Appendix A.
} 
More specifically, the cost-effective subglobal carbon budget may require (a) regulation in both periods (rather in the first period only), (b) taxing consumer demand (which is not part of the global policy) and (c) subsidizing rather than taxing emissions or, correspondingly, relaxing rather than tightening emission caps. In addition, the incidence of cost-effective carbon budget policy has some unexpected features: In comparison to laissez-faire, fossil fuel and second-period consumption may become more rather than less expensive and the free riding countries may lose, even more than the climate coalition.

Finally, it is worth mentioning that we have abstracted from many real-world complexities such as fossil-fuel saving technical change, renewable substitutes, abatement technologies, a time horizon beyond two periods, stock-dependent extraction costs or capital accumulation. However, since our present stylized model provides only very limited analytical insights into the properties and patterns of subglobal cost-effective carbon-budget policy, it is clear that including further relevant real-world complexities would render intractable the analysis without yielding additional informative results. More work is necessary on the characterization of cost-effective subglobal carbon-budget policy, but in our view this work should be done in large-scale, less stylized models which are calibrated with sound empirical data.

\section{References}

Ackerman, F. (2004), 'Priceless benefits, costly mistakes: What's wrong with cost-benefit analysis?', Post-Autistic Economics Review 25.

Bohm, P. (1993), 'Incomplete international cooperation to reduce $\mathrm{CO}_{2}$ emissions: alternative policies', Journal of Environmental Economics and Management 24, 258-271.

Copeland, B. and M.S. Taylor (2005), 'Free trade and global warming: a trade theory view of the Kyoto Protocol', Journal of Environmental Economics and Management 49, 205-234.

Council of the European Union (2005), European Council Brussels, 22 and 23 March 2005, Presidency conclusions 7619/05 REV1.

Di Maria, C. and E. van der Werf (2008), 'Carbon leakage revisted: Unilateral climate policy with directed technical change', Environmental and Resource Economics 39, 5574.

Eichner, T. and R. Pethig (2010), 'Carbon leakage, the green paradox and perfect future markets', International Economic Review, forthcoming. 
Gerlagh, R. (2010), 'Too much oil', CESifo Economic Studies, forthcoming.

Golombek, R. and M. Hoel (2004), 'Unilateral emission reductions and cross-country spillovers', The B.E. Journal of Economic Analysis and Policy 0(2).

Hoel, M. (1991), 'Global environmental problems: The effects of unilateral actions taken by one country', Journal of Environmental Economics and Management 20, 55-70.

Ishikawa, J. and K. Kiyono (2006), 'Greenhouse-gas emissions controls in an open economy', International Economic Review 47, 431-450.

Kalkuhl, M. and O. Edenhofer (2010), 'Prices vs. quantities and the intertemporal dynamics of the climate rent', Conference Paper WCERE 2010.

Lave, L. (1996), 'Benefit cost analysis: Do the benefits exceed the costs?', in R.W. Hahn Risks, Costs and Lives Saved: Getting Better Results from Regulation, 104-134, Oxford University Press.

Meinshausen, M., Meinshausen, N., Hare, W., Raper, S.B.C., Frieler, K., Knutti, R., Frame, D.J. and M.R. Allen (2009), 'Greenhouse-gas emission targets for limiting global warming to $2^{\circ} \mathrm{C}^{\prime}$, Nature $458,1158-1163$.

Sinclair, P. (1992), 'High does nothing and rising is worse: Carbon taxes should be kept declining to cut harmful emissions', Manchester School 60, 41-52.

Sinclair, P. (1994), 'On the optimum trend of fossil fuel taxation', Oxford Economic Papers $46,869-877$.

Sinn, H.-W. (2008), 'Public policies against global warming: a supply side approach', International Tax and Public Finance 15, 360-394.

UNFCCC (1992), United Nations Framework Convention on Climate Change, Rio De Janeiro.

UNFCCC (2009), 'Decision-/CP15', Copenhagen Accord, Denmark (December 18).

van der Ploeg, F. and C. Withagen (2009), 'Is there really a green paradox?' Technical Report, OxCarre Research Paper 35.

WBGU (2009), Kassensturz für den Weltklimavertrag - Der Budgetansatz, Sondergutachten. 


\section{Appendix}

\section{A. Proof of Proposition 2}

Consider first the supply-side partial equilibrium established by the equations

$$
\begin{aligned}
e_{A 1}+e_{B 1} & =\bar{e}_{1}, \quad e_{A 2}+e_{B 2}=\bar{e}_{2}:=\bar{e}-\bar{e}_{1}, \\
X_{e_{A 1}}^{A}\left(e_{A 1}\right) & =p_{e}+\pi_{A 1}, \\
X_{e_{B 1}}^{B}\left(\bar{e}_{1}-e_{A 1}\right) & =p_{e} \\
p_{x} X_{e_{A 2}}^{A}\left(e_{A 2}\right) & =p_{e}+\pi_{A 2}, \\
p_{x} X_{e_{B 2}}^{B}\left(\bar{e}_{2}-e_{A 2}\right) & =p_{e} .
\end{aligned}
$$

These equations determine $p_{e}, p_{x}, \pi_{A 1}, \pi_{A 2}$ and $x_{i t}^{s}$ for $i=A, B$ and $t=1,2$ for every $\left(e_{A 1}, e_{A 2}\right) \in\left[0, \bar{e}_{1}\right] \times\left[0, \bar{e}_{2}\right]$. That equilibrium is partial because the demand for good $X$ still needs to be specified in order to establish equilibrium on the commodity markets, ${ }^{19}$

$$
x_{A 1}+x_{B 1}=x_{A 1}^{s}+x_{B 1}^{s} .
$$

The CES utility functions yield the demands

$$
\begin{aligned}
x_{A 1} & =\frac{\left(\frac{\gamma_{1} p_{x}}{(1+\tau) \gamma_{2}}\right)^{\sigma}\left(y_{A o}+\tau x_{A 1}\right)}{(1+\tau)\left(\frac{\gamma_{1} p_{x}}{(1+\tau) \gamma_{2}}\right)^{\sigma}+p_{x}}=\frac{\left(\gamma_{1} p_{x}\right)^{\sigma} y_{A o}}{\left(\gamma_{1} p_{x}\right)^{\sigma}+(1+\tau)^{\sigma} \gamma_{2}^{\sigma} p_{x}}, \\
x_{B 1} & =\frac{\left(\frac{\gamma_{1} p_{x}}{\gamma_{2}}\right)^{\sigma} y_{B}}{p_{x}+\left(\frac{\gamma_{1} p_{x}}{\gamma_{2}}\right)^{\sigma}}
\end{aligned}
$$

where $y_{A o}$ and $y_{B}$ are incomes (see (10)) with $y_{A o}$ representing income before recycled tax revenue $\tau x_{A 1}$. Note that if $\sigma>0$ and $\tau \in \mathbb{R}, x_{A 1}$ in (A7) and $x_{B 1}$ in (A8) are fully determined for every $\left(e_{A 1}, e_{A 2}\right) \in\left[0, \bar{e}_{1}\right] \times\left[0, \bar{e}_{2}\right]$.

We first investigate how $x_{B 1}$ varies with $\sigma$. Since utility maximization implies

$$
\frac{x_{i 1}}{x_{i 2}}=\left(\frac{\gamma_{1} p_{x}}{\gamma_{2}}\right)^{\sigma} \quad(i=A, B),
$$

the straightforward conclusion from (A9) and constant $y_{B}$ is

$$
\frac{\mathrm{d} x_{B 1}}{\mathrm{~d} \sigma}\left\{\begin{array}{l}
>0, \text { if }\left(\gamma_{1} p_{x} / \gamma_{2}\right)>1 \quad\left(\text { and } x_{B 1} \rightarrow y_{B}, \text { if } \sigma \rightarrow \infty\right) \\
=0, \text { if }\left(\gamma_{1} p_{x} / \gamma_{2}\right)=1, \\
<0, \text { if }\left(\gamma_{1} p_{x} / \gamma_{2}\right)<1 \quad\left(\text { and } x_{B 1} \rightarrow 0, \text { if } \sigma \rightarrow \infty\right) .
\end{array}\right.
$$

\footnotetext{
${ }^{19}$ If (A6) is satisfied, the second-period market for good $X$ is also in equlibrium owing to Walras law.
} 
Consequently, disregarding the knife-edge case $\left(\gamma_{1} p_{x} / \gamma_{2}\right)=1$ we find that for every $\left(e_{A 1}, e_{A 2}\right)$ there is some set $S \subset \mathbb{R}$ with non-empty interior such that

$$
x_{B 1} \leq x_{A 1}^{s}+x_{B 1}^{s} \quad \forall \sigma \in S .
$$

Since $x_{A 1} \geq 0$, (A11) is clearly a necessary condition for (A6). Given (A11) sufficient for (A6) is $x_{A 1}=x_{A 1}^{s}+x_{B 1}^{s}-x_{B 1}$. For $\tau=0$ this equality will not hold, in general. But $x_{A 1}$ varies with $\tau$. Differentiation of (A7) with respect to $\tau$ yields

$$
\frac{\mathrm{d} x_{A 1}}{\mathrm{~d} \tau}=-\frac{\left(\gamma_{1} p_{x}\right)^{\sigma} y_{A o} \sigma(1+\tau)^{\sigma-1}}{\left[\left(\gamma_{1} p_{x}\right)^{\sigma}+(1+\tau)^{\sigma} \gamma_{2}^{\sigma} p_{x}\right]^{2}} \quad \text { and } \quad \lim _{\sigma \rightarrow 0} \frac{\mathrm{d} x_{A 1}}{\mathrm{~d} \tau}=0
$$

It follows that if $\sigma \in S$ and $x_{A 1} \neq x_{A 1}^{s}+x_{B 1}^{s}-x_{B 1}$ for $\tau=0$, one can change the magnitude of $x_{A 1}$ by an appropriate choice of $\tau$ such that (A6) is satisfied. This completes the proof of Proposition 2.

\section{B. Proof of Proposition 3}

The competitive equilibrium, when country $A$ operates cap and trade systems in both periods and when first-period consumption is taxed in country $A$ is characterized by the following equations

$$
\begin{aligned}
X_{e_{A 1}}^{A}-p_{e}-\pi_{A 1} & =0, \\
X_{e_{B 1}}^{B}-p_{e} & =0, \\
p_{x} X_{e_{A 2}}^{A}-p_{e}-\pi_{A 2} & =0, \\
p_{x} X_{e_{B 2}}^{B}-p_{e} & =0, \\
e_{A 1}-\bar{e}_{A 1} & =0, \\
e_{A 2}-\bar{e}_{A 2} & =0, \\
e_{t}-e_{A t}-e_{B t} & =0, \quad t=1,2, \\
\bar{e}-e_{1}-e_{2} & =0, \\
X^{A}\left(e_{A 1}\right)-x_{A 1}+p_{x}\left[X^{A}\left(e_{A 2}\right)-x_{A 2}\right]+p_{e} \Delta e_{A} & =0, \\
X^{B}\left(e_{B 1}\right)-x_{B 1}+p_{x}\left[X^{B}\left(e_{B 2}\right)-x_{B 2}\right]+p_{e} \Delta e_{B} & =0, \\
X^{A}\left(e_{A 2}\right)+X^{B}\left(e_{B 2}\right)-x_{A 2}-x_{B 2} & =0, \\
\frac{U_{x_{A 2}}-\frac{p_{x}}{1+\tau}}{U_{x_{A 1}}} & =0, \\
\frac{U_{x_{B 2}}-p_{x}}{U_{x_{B 1}}} & =0,
\end{aligned}
$$

where $\Delta e_{i}:=\alpha_{i} \bar{e}-e_{i 1}-e_{i 2}$ for $i=A, B$. The endogenous variables determined by the 14 equations (B1)-(B13) are $e_{A 1}, e_{A 2}, e_{B 1}, e_{B 2}, e_{1}, e_{2} x_{A 1}, x_{A 2}, x_{B 1}, x_{B 2}, p_{e}, p_{x}, \pi_{A 1}$ and $\pi_{A 2}$. 
The emission caps $\bar{e}_{A 1}, \bar{e}_{A 2}$ and the tax rate $\tau$ are treated here as exogenous parameter. Total differentiation of (B1) - (B13) yields, after some rearrangement of terms,

$$
\begin{aligned}
& \frac{1}{\eta_{A 1}} \hat{e}_{A 1}-\delta_{1} \hat{p}_{e}-\left(1-\delta_{1}\right) \hat{\pi}_{A 1}=0, \\
& \frac{1}{\eta_{B 1}} \hat{e}_{B 1}-\hat{p}_{e}=0 \\
& \hat{p}_{x}+\frac{1}{\eta_{A 2}} \hat{e}_{A 2}-\delta_{2} \hat{p}_{e}-\left(1-\delta_{2}\right) \hat{\pi}_{A 2}=0, \\
& \hat{p}_{x}+\frac{1}{\eta_{B 2}} \hat{e}_{B 2}-\hat{p}_{e}=0, \\
& \hat{e}_{A 1}-\hat{\bar{e}}_{A 1}=0 \text {, } \\
& \hat{e}_{A 2}-\hat{\bar{e}}_{A 2}=0 \text {, } \\
& e_{1} \hat{e}_{1}-e_{A 1} \hat{e}_{A 1}-e_{B 1} \hat{e}_{B 1}=0 \text {, } \\
& e_{2} \hat{e}_{2}-e_{A 2} \hat{e}_{A 2}-e_{B 2} \hat{e}_{B 2}=0 \text {, } \\
& e_{1} \hat{e}_{1}+e_{2} \hat{e}_{2}=0 \\
& \pi_{A 1} e_{A 1} \hat{e}_{A 1}+\pi_{A 2} e_{A 2} \hat{e}_{A 2}-x_{A 1} \hat{x}_{A 1}-p_{x} x_{A 2} \hat{x}_{A 2}+\Delta e_{A} p_{e} \hat{p}_{e}+\Delta x_{A 2} p_{x} \hat{p}_{x}=0, \\
& -x_{B 1} \hat{x}_{B 1}-p_{x} x_{B 2} \hat{x}_{B 2}+\Delta e_{B} p_{e} \hat{p}_{e}+\Delta x_{B 2} p_{x} \hat{p}_{x}=0, \\
& \left(p_{e}+\pi_{A 2}\right) e_{A 2} \hat{e}_{A 2}+p_{e} e_{B 2} \hat{e}_{B 2}-p_{x} x_{A 2} \hat{x}_{A 2}-p_{x} x_{B 2} \hat{x}_{B 2}=0, \\
& \hat{x}_{A 2}-\hat{x}_{A 1}+\hat{p}_{x} \sigma-\frac{\sigma \tau}{1+\tau} \hat{\tau}=0, \\
& \hat{x}_{B 2}-\hat{x}_{B 1}+\hat{p}_{x} \sigma=0,
\end{aligned}
$$

where $\delta_{t}:=\frac{p_{e}}{p_{e}+\pi_{t}}, \Delta x_{i t}:=x_{i t}^{s}-x_{i t}$ and $\eta_{i t}:=X_{e_{i t}}^{i} /\left(e_{i t} X_{e_{i t} e_{i t}}^{i}\right)$ for $t=1,2$ and $i=A, B$. Next, we derive the comparative static results of increases in $\tau$ when the emission caps are constant. For that purpose set $\hat{\bar{e}}_{A 1}=\hat{\bar{e}}_{A 2}=0$ and insert (B26) in (B23) and (B27) in (B24) to obtain

$$
\begin{aligned}
& \hat{x}_{A 2}=\frac{\Delta e_{A} p_{e}}{y_{A}} \hat{p}_{e}+\frac{p_{x} \Delta x_{A 2}-\sigma x_{A 1}}{y_{A}} \hat{p}_{x}+\frac{\sigma \tau x_{A 1}}{(1+\tau) y_{A}} \hat{\tau}, \\
& \hat{x}_{B 2}=\frac{\Delta e_{B} p_{e}}{y_{B}} \hat{p}_{e}+\frac{p_{x} \Delta x_{B 2}-\sigma x_{B 1}}{y_{B}} \hat{p}_{x},
\end{aligned}
$$

where $\Delta e_{i}:=\alpha_{i} \bar{e}-e_{i 1}-e_{i 2}$ for $i=A, B$. Using (B20) in (B15), and (B21), (B22) in (B17) to get

$$
\begin{aligned}
\hat{p}_{e} & =\frac{e_{1}}{e_{B 1} \eta_{B 1}} \hat{e}_{1}, \\
\hat{p}_{x} & =\frac{e_{B 1} \eta_{B 1}+e_{B 2} \eta_{B 2}}{e_{B 1} \eta_{B 1} e_{B 2} \eta_{B 2}} e_{1} \hat{e}_{1} .
\end{aligned}
$$

Inserting $\hat{e}_{B 2} e_{B 2}=-\hat{e}_{1} e_{1}$ in (B25) yields

$$
-p_{e} e_{1} \hat{e}_{1}=p_{x} \sum_{i=A, B} x_{i 2} \hat{x}_{i 2}
$$


Making use of (B28) and (B29) in (B32) we obtain

$$
\begin{aligned}
\frac{p_{x} x_{A 2} x_{A 1} \sigma \mathrm{d} \tau}{(1+\tau) y_{A}} & =-p_{e} e_{1} \hat{e}_{1}-\left(\frac{p_{x} x_{A 2}}{y_{A}}-\frac{p_{x} x_{B 2}}{y_{B}}\right) \Delta e_{A} p_{e} \hat{p}_{e} \\
& -\left(\frac{p_{x} x_{A 2}}{y_{A}}-\frac{p_{x} x_{B 2}}{y_{B}}\right) p_{x} \Delta x_{A 2} \hat{p}_{x}+\sigma\left(\frac{p_{x} x_{A 1} x_{A 2}}{y_{A}}+\frac{p_{x} x_{B 1} x_{B 2}}{y_{B}}\right) \hat{p}_{x}(
\end{aligned}
$$

which with the help of (B30) and (B31) can be rearranged to

$$
\begin{aligned}
\frac{p_{x} x_{A 1} x_{A 2} \sigma \mathrm{d} \tau}{(1+\tau) y_{A} \mathrm{~d} e_{1}} & =-p_{e}+\frac{1}{e_{B 2} \eta_{B 2}}\left(\frac{p_{x} x_{A 2}}{y_{A}}-\frac{p_{x} x_{B 2}}{y_{B}}\right) \Delta e_{A} \\
& +\left(\frac{p_{x} x_{A 2}}{y_{A}}-\frac{p_{x} x_{B 2}}{y_{B}}\right) \Delta x_{A 1}\left(\frac{e_{B 1} \eta_{B 1}+e_{B 2} \eta_{B 2}}{e_{B 1} \eta_{B 1} e_{B 2} \eta_{B 2}}\right) \\
& +\sigma\left(\frac{p_{x} x_{A 1} x_{A 2}}{y_{A}}+\frac{p_{x} x_{B 1} x_{B 2}}{y_{B}}\right)\left(\frac{e_{B 1} \eta_{B 1}+e_{B 2} \eta_{B 2}}{e_{B 1} \eta_{B 1} e_{B 2} \eta_{B 2}}\right) .
\end{aligned}
$$

For CES functions (19) it holds $x_{A 1}=x_{A 2}\left(\frac{\gamma_{1} p_{x}}{\gamma_{2}(1+\tau)}\right)^{\sigma}, x_{B 1}=x_{B 2}\left(\frac{\gamma_{1} p_{x}}{\gamma_{2}}\right)^{\sigma}$ and hence

$$
\frac{p_{x} x_{A 2}}{x_{A 1}+p_{x} x_{A 2}}=\frac{p_{x}}{p_{x}+\left(\frac{\gamma_{1} p_{x}}{\gamma_{2}(1+\tau)}\right)^{\sigma}} \geq \frac{p_{x} x_{B 2}}{x_{B 1}+p_{x} x_{B 2}}=\frac{p_{x}}{p_{x}+\left(\frac{\gamma_{1} p_{x}}{\gamma_{2}}\right)^{\sigma}} .
$$

Inserting (B30) and (B31) in (B14) and (B16), respectively, we obtain

$$
\begin{aligned}
\hat{\pi}_{A 1} & =-\frac{\delta_{1}}{\left(1-\delta_{1}\right) e_{B 1} \eta_{B 1}} e_{1} \hat{e}_{1} \\
\hat{\pi}_{A 2} & =\left[\frac{1}{e_{B 1} \eta_{B 1}}+\frac{1}{\left(1-\delta_{2}\right) e_{B 2} \eta_{B 2}}\right] e_{1} \hat{e}_{1}
\end{aligned}
$$

We start from a symmetric laissez faire equilibrium without any policy, i.e. with $\Delta e_{A}=$ $\Delta x_{A 1}=\Delta x_{A 2}=\pi_{A 1}=\pi_{A 2}=\tau=0$. The comparative static results are summarized in Table 1.

\begin{tabular}{|c||c|c|c|c|c|c|c|}
\hline & $\mathrm{d} e_{F 1}$ & $\mathrm{~d} p_{e}$ & $\mathrm{~d} p_{x}$ & $\mathrm{~d} x_{B 2}$ & $\mathrm{~d} x_{A 2}$ & $\mathrm{~d} e_{A 1}=\mathrm{d} e_{A 2}$ & $\mathrm{~d} e_{B 1}=-\mathrm{d} e_{B 2}$ \\
\hline $\mathrm{d} \tau>0$ & - & + & + & - & + & 0 & - \\
\hline follows from eq. & $(\mathrm{B} 34)$ & $(\mathrm{B} 30)$ & $(\mathrm{B} 31)$ & $(\mathrm{B} 29)$ & $(\mathrm{B} 32)$ & & \\
\hline
\end{tabular}

\begin{tabular}{|c||c|c|c|c|c|}
\hline & $\mathrm{d} \Delta x_{A 2}=-\mathrm{d} \Delta x_{B 2}$ & $\mathrm{~d} \Delta e_{A}=\mathrm{d} \Delta e_{B}$ & $\mathrm{~d} \Delta x_{A 1}=\mathrm{d} \Delta x_{B 1}$ & $\mathrm{~d} \pi_{A 1}$ & $\mathrm{~d} \pi_{A 2}$ \\
\hline $\mathrm{d} \tau>0$ & - & 0 & + & - & + \\
\hline
\end{tabular}

Table 2: The comparative statics of increases in $\tau$

Next, we further increase the tax rate $(\tau>0$ and $\mathrm{d} \tau>0)$ and account for the information of Table 2, in especially $\Delta e_{A}=0$ and $\Delta x_{A 1}>0$. This comparative static analysis yields again the signs listed in Table 2.

Finally, we turn to the welfare changes. Inserting $\hat{x}_{A 2}$ from (B26) into $\mathrm{d} u_{A}=U_{x_{A 1}} x_{A 1} \hat{x}_{A 1}+$ $U_{x_{A 2}} x_{A 2} \hat{x}_{A 2}$ and using $U_{x_{A 1}}=\frac{\lambda_{A}}{1+\tau}$ and $U_{x_{A 2}}=\frac{\lambda_{A}}{p_{x}}$ we get

$$
\frac{\mathrm{d} u_{A}}{\lambda_{A}}=\left(\tau x_{A 1}+y_{A}\right) \hat{x}_{A 2}+(1+\tau) x_{A 1} \sigma \hat{p}_{x}-\sigma x_{A 1} \tau \hat{\tau}
$$


Taking advantage of (B28) and rearranging terms yields

$$
\frac{\mathrm{d} u_{A}}{\lambda_{A}}=\frac{\tau x_{A 1}+y_{A}}{y_{A}} p_{x} \Delta x_{A 2} \hat{p}_{x}+\frac{\tau x_{A 1} p_{x} x_{A 2} \sigma}{y_{A}} \hat{p}_{x}-\frac{\tau x_{A 1} p_{x} x_{A 2} \sigma}{(1+\tau) y_{A}} \hat{\tau}
$$

Next, we insert (B33) into (B39) to obtain

$$
\frac{\mathrm{d} u_{A}}{\lambda_{A}}=\tau p_{e} e_{F 1} \hat{e}_{F 1}-\frac{\tau \sigma x_{B 1} p_{x} x_{B 2}}{y_{B}} \hat{p}_{x}+\left(1+\tau-\frac{p_{x} x_{B 2}}{y_{B}}\right) p_{x} \Delta x_{A 2} \hat{p}_{x}
$$

which establishes $\mathrm{d} u_{A} / \mathrm{d} \tau<0$.

Using the same steps of rearrangements as above it is straightforward to show that

$$
\frac{\mathrm{d} u_{B}}{\lambda_{B}}=p_{x} \Delta x_{B 2} \hat{p}_{x}>0 .
$$

\section{Proof of Proposition 4}

Ad (a) and (b): Differentiation of (22) and $p_{x}=\frac{X_{e_{B 1}}^{B}\left(\bar{e}_{1}-e_{A 1}\right)}{X_{e_{B 2}}^{B}\left(\bar{e}_{2}-e_{A 2}\right)}$ yields

$$
\begin{aligned}
\frac{\mathrm{d} p_{e}}{\mathrm{~d} e_{A 1}} & =-X_{e_{B 1} e_{B 1}}^{B}, & \frac{\mathrm{d} p_{e}}{\mathrm{~d} e_{A 2}} & =0 \\
\frac{\mathrm{d} p_{x}}{\mathrm{~d} e_{A 1}}=-\frac{p_{x}}{p_{e}} X_{e_{B 1} e_{B 1}}^{B} & =-\frac{p_{x}}{e_{B 1} \eta_{B 1}}, & \frac{\mathrm{d} p_{x}}{\mathrm{~d} e_{A 2}} & =\frac{p_{x}^{2}}{p_{e}} X_{e_{B 2} e_{B 2}}^{B}=\frac{p_{x}}{e_{B 2} \eta_{B 2}},
\end{aligned}
$$

where $\eta_{B t}:=\frac{X_{e_{B t}}^{B}}{e_{B t} X_{e_{B t} e_{B t}}^{B}}<0$ for $t=1,2$.

The consumer in country $B$ maximizes utility $U^{B}\left(x_{B 1}, x_{B 2}\right)=\left(\gamma_{1} x_{B 1}^{\frac{\sigma_{B}-1}{\sigma_{B}}}+\gamma_{2} x_{B 2}^{\frac{\sigma_{B}-1}{\sigma_{B}}}\right)^{\frac{h \sigma_{B}}{\sigma_{B}-1}}$ subject to

$$
x_{B 1}+p_{x} x_{B 2}=X\left(e_{B 1}\right)+p_{x} X\left(e_{B 2}\right)+p_{e}\left(\alpha_{B} \bar{e}-e_{B 1}-e_{B 2}\right)=: y_{B}
$$

The first-order condition is given by

$$
\frac{x_{B 1}}{x_{B 2}}=\bar{\gamma} p_{x}^{\sigma_{B}}
$$

where $\bar{\gamma}:=\left(\frac{\gamma_{1}}{\gamma_{2}}\right)^{\sigma_{B}}$. Using the budget constraint (C3) in (C4) we obtain

$$
\begin{aligned}
x_{B 1} & =\frac{\bar{\gamma} p_{x}^{\sigma_{B}} y_{B}}{p_{x}+\bar{\gamma} p_{x}^{\sigma_{B}}}, \\
x_{B 2} & =\frac{y_{B}}{p_{x}+\bar{\gamma} p_{x}^{\sigma_{B}}} .
\end{aligned}
$$

Next, we differentiate $y_{B}=X^{B}\left(\bar{e}_{1}-e_{A 1}\right)+p_{x} X^{B}\left(\bar{e}_{2}-e_{A 2}\right)-p_{e}\left(\alpha_{A} \bar{e}-e_{A 1}-e_{A 2}\right)$ and use (22), (24), (C1) and (C2) to obtain

$$
\begin{aligned}
\frac{\mathrm{d} y_{B}}{\mathrm{~d} e_{A 1}} & =x_{B 2}^{s} \frac{\mathrm{d} p_{x}}{\mathrm{~d} e_{A 1}}-\Delta e_{A} \frac{\mathrm{d} p_{e}}{\mathrm{~d} e_{A 1}}=\frac{\left(y_{B}-x_{B 1}^{s}\right)}{p_{x}} \frac{\mathrm{d} p_{x}}{\mathrm{~d} e_{A 1}}, \\
\frac{\mathrm{d} y_{B}}{\mathrm{~d} e_{A 2}} & =x_{B 2}^{s} \frac{\mathrm{d} p_{x}}{\mathrm{~d} e_{A 2}} .
\end{aligned}
$$


Differentiation of (C5)-(C6) and making use of (C4)-(C6) yields

$$
\begin{aligned}
\frac{\mathrm{d} x_{B 1}}{\mathrm{~d} e_{A t}} & =\frac{\bar{\gamma} p_{x}^{\sigma_{B}}}{p_{x}+\bar{\gamma} p_{x}^{\sigma_{B}}} \frac{\mathrm{d} y_{B}}{\mathrm{~d} e_{A t}}+\frac{\bar{\gamma} y_{B}\left(\sigma_{B}-1\right) p_{x}^{\sigma_{B}}}{\left(p_{x}+\bar{\gamma} p_{x}^{\sigma_{B}}\right)^{2}} \frac{\mathrm{d} p_{x}}{\mathrm{~d} e_{A t}} \\
& =\frac{x_{B 1}}{y_{B}}\left[\frac{\mathrm{d} y_{B}}{\mathrm{~d} e_{A t}}+\left(\sigma_{B}-1\right) x_{B 2} \frac{\mathrm{d} p_{x}}{\mathrm{~d} e_{A t}}\right], \\
\frac{\mathrm{d} x_{B 2}}{\mathrm{~d} e_{A t}} & =\frac{1}{p_{x}+\bar{\gamma} p_{x}^{\sigma_{B}}} \frac{\mathrm{d} y_{B}}{\mathrm{~d} e_{A t}}-\frac{y_{B}\left(1+\sigma_{B} \bar{\gamma} p_{x}^{\sigma_{B}-1}\right)}{\left(p_{x}+\bar{\gamma} p_{x}^{\sigma_{B}}\right)^{2}} \frac{\mathrm{d} p_{x}}{\mathrm{~d} e_{A t}} \\
& =\frac{x_{B 2}}{y_{B}}\left[\frac{\mathrm{d} y_{B}}{\mathrm{~d} e_{A t}}-\left(x_{B 2}+\frac{\sigma_{B} x_{B 1}}{p_{x}}\right) \frac{\mathrm{d} p_{x}}{\mathrm{~d} e_{A t}}\right],
\end{aligned}
$$

for $t=1$, 2. Inserting $(\mathrm{C} 7),(\mathrm{C} 8)$ and $(\mathrm{C} 2)$ in $(\mathrm{C} 9)$ and $(\mathrm{C} 10)$ we obtain after rearrangement of terms

$$
\begin{aligned}
\frac{\mathrm{d} x_{B 1}}{\mathrm{~d} e_{A 1}} & =-\frac{x_{B 1}}{y_{B} e_{B 1} \eta_{B 1}}\left[y_{B}-x_{B 1}^{s}+\left(\sigma_{B}-1\right) p_{x} x_{B 2}\right] \\
\frac{\mathrm{d} x_{B 2}}{\mathrm{~d} e_{A 1}} & =-\frac{x_{B 2}}{y_{B} e_{B 1} \eta_{B 1}}\left[y_{B}-x_{B 1}^{s}-p_{x} x_{B 2}-\sigma_{B} x_{B 1}\right] \\
\frac{\mathrm{d} x_{B 1}}{\mathrm{~d} e_{A 2}} & =\frac{p_{x} x_{B 1}}{y_{B} e_{B 2} \eta_{B 2}}\left[\Delta x_{B 2}+\sigma_{B} x_{B 2}\right] \\
\frac{\mathrm{d} x_{B 2}}{\mathrm{~d} e_{A 2}} & =\frac{x_{B 2}}{y_{B} e_{B 2} \eta_{B 2}}\left[p_{x} \Delta x_{B 2}-\sigma_{B} x_{B 1}\right]
\end{aligned}
$$

Maximizing country $A$ 's welfare w.r.t. $e_{A 1}$ and $e_{A 2}$ yields the first-order condition

$$
\frac{U_{x_{A 2}}^{A}}{U_{x_{A 1}}^{A}}=-\frac{\frac{\mathrm{d} x_{A 1}}{\mathrm{~d} e_{A 1}}}{\frac{\mathrm{d} x_{A 2}}{\mathrm{~d} e_{A 1}}}=-\frac{\frac{\mathrm{d} x_{A 1}}{\mathrm{~d} e_{A 2}}}{\frac{\mathrm{d} x_{A 2}}{\mathrm{~d} e_{A 2}}} .
$$

Differentiation of $x_{A 1}=X^{A}\left(e_{A 1}\right)+X^{A}\left(\bar{e}_{1}-e_{A 1}\right)-x_{B 1}$ and $x_{A 2}=X^{A}\left(e_{A 2}\right)+X^{A}\left(\bar{e}_{2}-e_{A 2}\right)-x_{B 2}$ yields after rearrangement of terms

$$
\begin{aligned}
\frac{\mathrm{d} x_{A 1}}{\mathrm{~d} e_{A 1}} & =\pi_{A 1}-\frac{x_{B 1}}{y_{B} e_{B 1} \eta_{B 1}}\left(\Delta x_{B 1}-\sigma_{B} p_{x} x_{B 2}\right), \\
\frac{\mathrm{d} x_{A 2}}{\mathrm{~d} e_{A 1}} & =-\frac{x_{B 2}}{y_{B} e_{B 1} \eta_{B 1}}\left(\Delta x_{B 1}+\sigma_{B} x_{B 1}\right), \\
\frac{\mathrm{d} x_{A 1}}{\mathrm{~d} e_{A 2}} & =-\frac{p_{x} x_{B 1}}{y_{B} e_{B 2} \eta_{B 2}}\left(\Delta x_{B 2}+\sigma_{B} x_{B 2}\right), \\
\frac{\mathrm{d} x_{A 2}}{\mathrm{~d} e_{A 2}} & =\frac{\pi_{A 2}}{p_{x}}-\frac{x_{B 2}}{y_{B} e_{B 2} \eta_{B 2}}\left(p_{x} \Delta x_{B 2}-\sigma_{B} x_{B 1}\right) .
\end{aligned}
$$

Inserting $U_{x_{A 2}}^{A}=U_{x_{A 1}}^{A} \frac{p_{x}}{1+\tau}$ in $U_{x_{A 2}}^{A} \frac{\mathrm{d} x_{A 2}}{\mathrm{~d} e_{A t}}+U_{x_{A 1}}^{A} \frac{\mathrm{d} x_{A 1}}{\mathrm{~d} e_{A t}}=0$ for $t=1,2$ yields

$$
p_{x} \frac{\mathrm{d} x_{A 2}}{\mathrm{~d} e_{A t}}+(1+\tau) \frac{\mathrm{d} x_{A 1}}{\mathrm{~d} e_{A t}}=0 \quad \text { for } t=1,2 .
$$

Making use of (C16) and (C17) [(C18) and (C19)] in (C20) and rearranging terms establishes

$$
\begin{aligned}
(1+\lambda \tau) \Delta x_{B 1}-\tau \lambda \sigma_{B} p_{x} x_{B 2} & =(1+\tau) \pi_{A 1} e_{B 1} \eta_{B 1} \\
(1+\lambda \tau) p_{x} \Delta x_{B 2}+\tau \lambda \sigma_{B} p_{x} x_{B 2} & =\pi_{A 2} e_{B 2} \eta_{B 2}
\end{aligned}
$$


where $\lambda:=x_{B 1} / y_{B} \in[0,1]$ Finally, adding (C21) and (C22) we get

$$
(1+\lambda \tau) \Delta e_{A}=(1+\tau) \pi_{A 1} e_{B 1} \eta_{B 1}+\pi_{A 2} e_{B 2} \eta_{B 2} .
$$

Accounting for $(1+\tau) \geq 0$ and $(1+\lambda \tau) \geq 0$, Propsition 4 (a) and (b) immediately follows fom $(\mathrm{C} 23)$

Ad (c): Inserting (C16)-(C19) in (C15) we get

$$
\frac{U_{x_{A 2}}^{A}}{U_{x_{A 1}}^{A}}=\overbrace{\overbrace{=: C}^{-\pi_{A 1}+\frac{x_{B 1}}{y_{B} e_{B 1} \eta_{B 1}}\left(\Delta x_{B 1}-\sigma_{B} p_{x} x_{B 2}\right)}}^{=: A} p_{x}
$$

and

$$
\frac{U_{x_{A 2}}^{A}}{U_{x_{A 1}}^{A}}=\underbrace{\frac{\overbrace{-\frac{x_{B 1}}{y_{B} e_{B 2} \eta_{B 2}}\left[\Delta x_{B 2}+\sigma_{B} x_{B 2}\right]}^{\underbrace{B}_{\frac{\pi_{A 2}}{p_{x}}+\frac{x_{B 2}}{y_{B} e_{B 2} \eta_{B 2}}\left[p_{x} \Delta x_{B 2}-\sigma_{B} x_{B 1}\right]}}}{=: B}}_{:=D} p_{x} .
$$

Suppose that $\sigma_{B} \geq 1$, then we have $A>0, B>0, C>0, D>0$ and it holds

$$
\tau \gtreqless 0 \Longleftrightarrow A \lesseqgtr C \quad \Longleftrightarrow \quad B \lesseqgtr D
$$

Making use of the definitions of $A, B, C, D$ establishes

$$
\tau \gtreqless 0 \quad \Longleftrightarrow \quad-\Delta x_{B 1} \lesseqgtr-\pi_{A 1} e_{B 1} \eta_{B 1} \quad \Longleftrightarrow \quad p_{x} \Delta x_{B 2} \lesseqgtr \pi_{A 2} e_{B 2} \eta_{B 2} .
$$

